\title{
COMPREHENSIVE MANAGEMENT OF \\ PELVIC FLOOR DYSFUNCTION IN WOMEN
}

A Dissertation presented to

The Faculty of the Graduate School

As the University of Missouri

In Partial Fulfillment

of the Requirements for the Degree

Doctor of Philosophy

by

JULIE A. STARR

Dr. Marilyn Rantz, Dissertation Supervisor

MAY 2017 
The undersigned, appointed by the Dean of the Graduate School, have examined the dissertation entitled:

\section{COMPREHENSIVE MANAGEMENT OF PELVIC FLOOR DYSFUNCTION IN WOMEN}

presented by Julie A. Starr

a candidate for the degree of Doctor of Philosophy and hereby certify that, in their

opinion, it is worthy of acceptance.

Dr. Marilyn Rantz

Dr. Gregory Alexander

Dr. Lorraine Phillips

Raymond Foster M.D. 


\section{DEDICATION}

This research is dedicated to all women whose symptoms of pelvic floor dysfunction have gone unidentified, untreated or who have, for whatever reason been unable to share them with their health care providers. Treatment options for these sometimes debilitating symptoms are often inaccessible or limited to medications or treatments that do not treat the underlying problem associated with these diagnoses. I am in hopes that these findings will add to the limited amount of scientific evidence in the literature and result in accessible and cost effective treatment for women with these life-altering conditions.

This work is especially dedicated to those women who were victims of childhood sexual abuse, as I truly believe that the physical and emotional trauma that results from such abuse is a major contributing factor to symptoms of pelvic floor dysfunction in this group of women. Physical trauma to the pelvic floor during childhood can affect the normal development of the bladder, rectum and reproductive system resulting in permanent physical changes to specific organs. In addition, the emotional instability that often results from abuse can make dealing with symptoms of pelvic floor dysfunction even more challenging. 


\section{ACKNOWLEDGMENTS}

This dissertation represents the cumulative knowledge of my graduate studies. This accomplishment would not be possible without the invaluable support from so many during the five years of my doctoral training. First, I would like to thank my parents Frank and Susan Stork who are fine examples of people who have dedicate their lives to helping others. Their steadfast commitment to each other and their loyalty and love toward their family and friends has provided a fine example of how doing for others can lead to a rich and fulfilling life. I am also exceedingly grateful to my amazing daughters Taylor, Rachael and Ellissa who have offered endless words of encouragement throughout this process. While navigating the mysteries of their own new adult lives, they always found time to reach out with words of love and support. I am especially grateful to my domestic partner Doug whom I owe a tremendous debt of appreciation for the many sacrifices he has made over the past five years to keep me moving forward in the process. And a big thanks to his boys, Carter and Dalton who were always eager to ask about my progress and willing to tiptoe around when I was working on a manuscript.

My doctoral committee has been truly amazing. I would like to thank Dr. Marilyn Rantz for her patience, encouragement and ongoing feedback throughout my doctoral studies and the dissertation process. A big thanks to Dr. Lorraine Phillips for her diligence in keeping me on track with my research methods. Her expertise has provided me with a knowledge base that will help to drive many future study designs. Dr. Gregory Alexander provided insight into the area of big data. I admire his knowledge and encouragement throughout this process. A special thanks to Raymond Foster M.D. who was a driving 
force in my dream of becoming a researcher. I truly valued our conversations regarding my research trajectory and his many ideas on how to continue advancing the science of pelvic floor dysfunction. I would also like to thank Dr. Colleen Galambos who shared invaluable insights into the field of social sciences. Her keen insights helped strengthen my understanding of the many social influences that effect women's health. I am also grateful for the skills and keen insights of Dr. Erma Drobnis who contributed her statistical expertise in assistance with data analysis. Each member of my committee has contributed uniquely to my academic development and for that, I am truly grateful.

While this dissertation has only one author, it truly reflects a research trajectory that involved a team effort. I would like to thank my professional colleagues at the Center for Female Continence and Advanced Pelvic Surgery who share a common passion and drive to enhance the quality of care at University of Missouri Health Care. This work could not have been realized without their dedication and passion for women with symptoms of pelvic floor dysfunction. 


\section{TABLE OF CONTENTS}

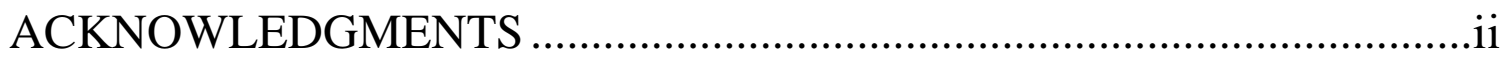

LIST OF ILLUSTRATIONS...................................................................vi

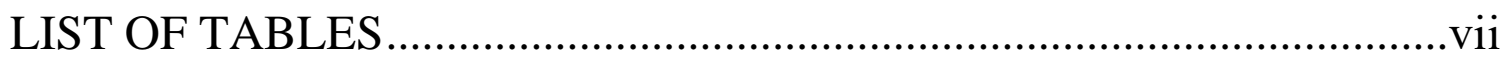

LIST OF ABBREVIATIONS ..............................................................viii

\section{CHAPTER}

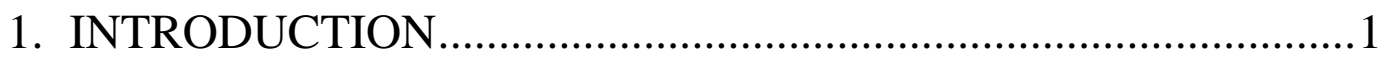

1.1 Background and Significance ......................................... 3

1.2 Retrospective Review .................................................6

2. REVIEW OF THE LITERATURE: HIGH TONE PELVIC FLOOR MUSCLE DYSFUNCTION ........................................10

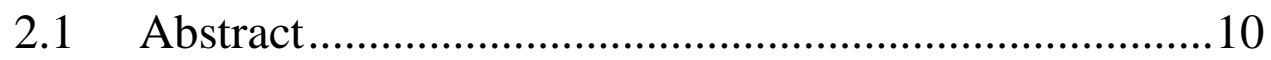

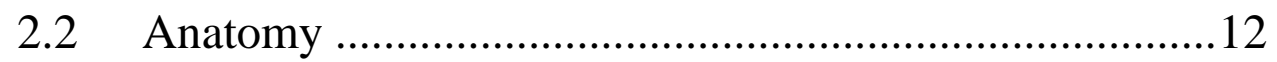

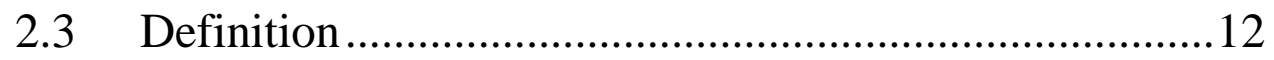

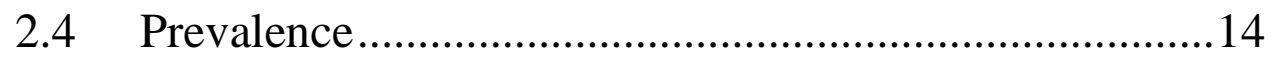

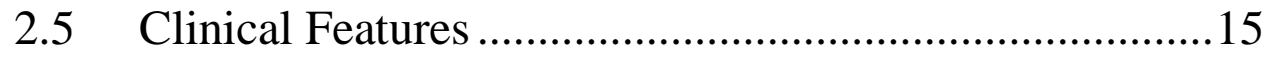

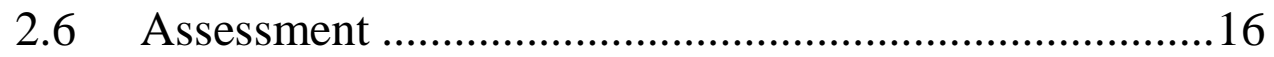

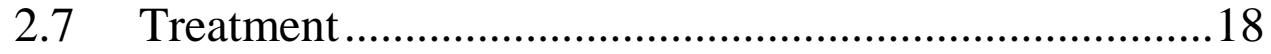

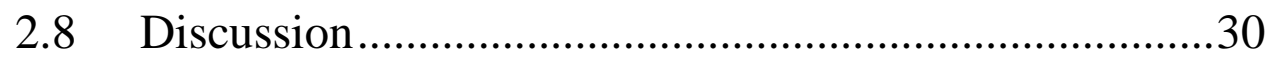

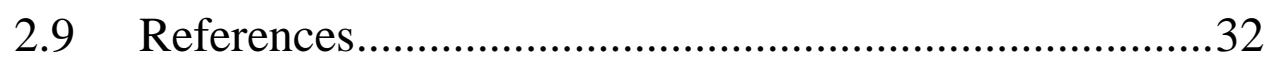

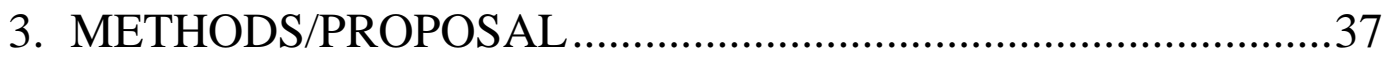


4. OUTCOMES OF COMPREHENSIVE MANAGEMENT OF PELVIC FLOOR DYSFUNCTION IN WOMEN:

A SECONDARY ANALYSIS..................................................50

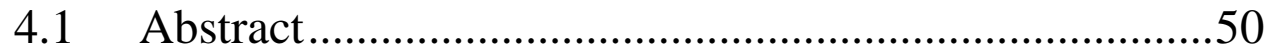

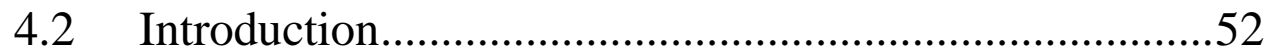

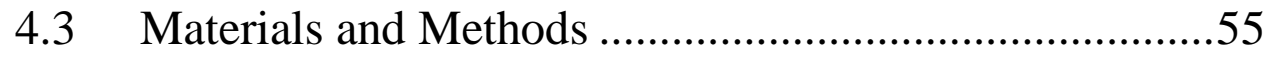

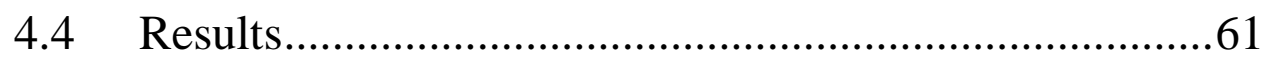

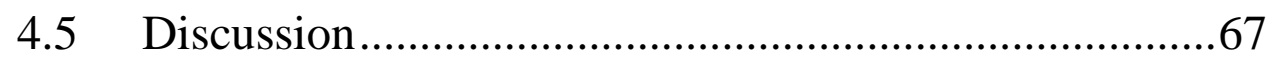

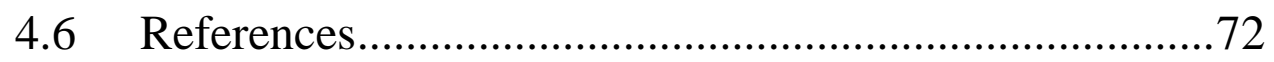

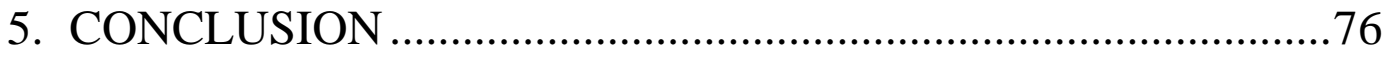

$5.1 \quad$ Summary …...............................................................

5.2 Significance of Dissertation Work .................................77

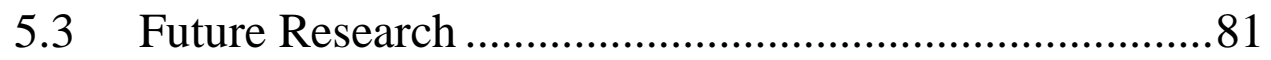

\section{APPENDICES}
A. PELVIC FLOOR DISTRESS INVENTORY (PFDI-20) ...............83
B. PELVIC FLOOR IMPACT QUESTIONNAIRRE (PFIQ-7)........84
C. PELVIC FLOOR THERAPY EVALUATION FORM..................85

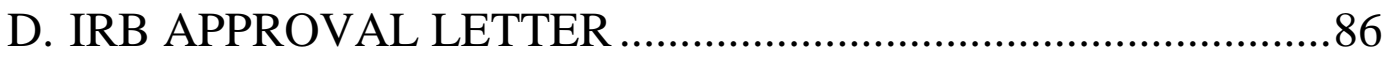

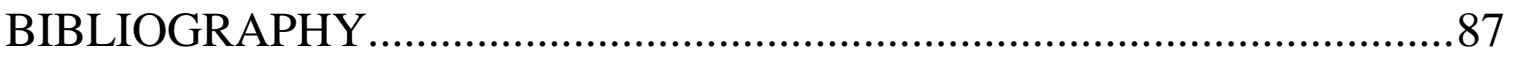

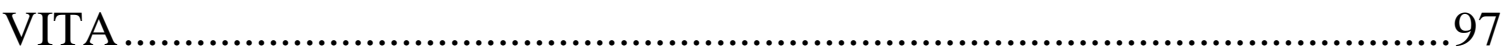




\section{LIST OF ILLUSTRATIONS}

4.1 Subject reported percentage urinary symptom improvement .................64

4.2 Subject reported percentage defecatory symptom improvement ...........64

4.3 Subject reported percentage pain symptom improvement .....................64 


\section{LIST OF TABLES}

3.1 Summary specific aims, hypotheses and overview of the analyses..........................45

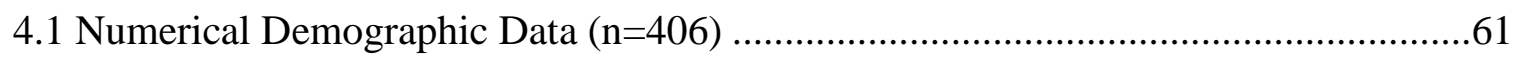

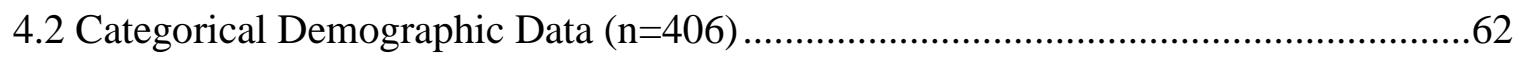

4.3 Percent in Urinary Symptom Improvement by ................................................63

4.4 Percent in Defecatory Symptom Improvement by VAS.....................................63

4.5 Percent in Pelvic Pain Symptom Improvement by VAS .......................................63

4.6 QOL Improvement Final Treatment ..........................................................65

4.7 QOL Improvement Final Treatment \& 6 Months ..................................................65

4.8 QOL Improvement Final Treatment \& 12 Months ..............................................65

4.9 QOL Improvement At All Time Points ...............................................................65

4.10 End of Treatment Exercise Frequency Symptom Improvement............................66

4.11 End of Treatment Bowel Program Compliance Symptom Improvement.................66 


\section{LIST OF ABBREVIATIONS}

\begin{tabular}{|c|c|}
\hline APRN & Advanced Practice Registered Nurse \\
\hline BoTN-A & Botulinum toxin $\mathrm{A}$ \\
\hline EGS & Electrogalvanic Stimulation \\
\hline EMG & Electromyography \\
\hline HTPFD & High Tone Pelvic Floor Dysfunction \\
\hline IRB & Institutional Review Board \\
\hline OB/GYN & Obstetrics and Gynecology \\
\hline PFD & Pelvic Floor Dysfunction \\
\hline PFDI-20 & Pelvic Floor Distress Inventory \\
\hline PFIQ-7 & Pelvic Floor Impact Questionnaire \\
\hline PFMT & Pelvic Floor Muscle Training \\
\hline PRN & As needed \\
\hline QOL & Quality of Life \\
\hline TID & $3 x$ day \\
\hline UI & Urinary Incontinence \\
\hline VAS & Visual Analog Scale \\
\hline
\end{tabular}




\section{CHAPTER ONE}

\section{Introduction}

Pelvic floor dysfunction (PFD) encompasses a broad spectrum of neuromuscular disorders of the pelvic floor, resulting in a wide array of functional problems in women. Abnormal function of the pelvic floor musculature is a poorly understood entity and often described as the mechanical and neurological disruption of the normal functional anatomy of the pelvic floor (Butrick, 2009; Davis \& Kumar, 2003; Finamore, 2008). It presents as low or high tone pelvic floor musculature and is often associated with symptoms of urinary and fecal incontinence, urinary urgency/frequency, voiding dysfunction, obstructed defecation, pelvic organ prolapse, sexual dysfunction and pelvic pain. It is thought to be a contributing factor in $70 \%$ of women who present with genitourinary, bowel, and sexual disorders (Wehbe, Whitmore, \& Kellogg-Spadt, 2010). Frequently cited contributory factors include pregnancy, obstetrical trauma, multi-parity, estrogen deficiency in menopause, previous pelvic floor surgery, coexisting medical conditions (e.g. diabetes and congenital tissue disorders), neurological disorders impairing pelvic floor function, and obesity related disorders increasing abdominal pressure (Butrick, 2009; Davis \& Kumar, 2003).

It is becoming increasingly common to offer nonsurgical treatment to women with PFD. Nonoperative management may include a variety of therapies such as pelvic floor muscle training (PFMT), biofeedback, electrical or electrogalvanic stimulation (EGS), constipation management, behavior modification, incontinence devices, and pharmacotherapy including antimuscarinic medications and vaginal estrogen. There is no 
generally accepted consensus for the correct approach to the nonoperative management of PFD, but a multifaceted approach is often used. A typical treatment plan includes several different therapeutic modalities that have been selected to provide the best chance of cure.

There is a paucity of literature evaluating the aggregate clinical effect of comprehensive, multimodal nonsurgical pelvic floor rehabilitation. Current research is primarily focused on the use of physical therapy administered by a physical therapist or physiotherapist which includes but is not limited to PFMT and biofeedback to treat urinary and fecal incontinence (Barroso, Ramos, Martins-Costa, Sanches, \& Muller, 2004; Bendana et al., 2009; Dumoulin \& Hay-Smith, 2010; Hay-Smith, Herderschee, Dumoulin, \& Herbison, 2012; Norton \& Cody, 2012; Rai, Cody, Alhasso, \& Stewart, 2012). The improvement in symptoms afforded by mono modal PFMT is modest, with approximately $43 \%$ reported improvement in outpatient non-group therapy (Hay-Smith et al., 2012).

A retrospective analysis of 728 women who underwent five sessions of pelvic floor rehabilitation with an advanced practice nurse (APRN) in an outpatient academic urogynecology clinic revealed a mean improvement of $80-85 \%$ in urinary, defecatory and pelvic pain complaints (Starr et al., 2013). These outcomes are significant, but what the researcher failed to do was to follow these women over time. Several questions remain unanswered including: 1) "How effective is comprehensive management of PFD by an APRN over time?" 2) "If symptom control was maintained, what variables predicted symptom stability?" There is a paucity of literature in the nonoperative treatment of women with PFD. The proposed study is an attempt to gain insight, into the complex 
management of these conditions and make a scientific contribution to the literature for non-surgical management of women with these life-altering symptoms.

\section{Background and Significance}

PFD includes symptoms of urinary incontinence, pelvic organ prolapse, anal incontinence, sensory abnormalities of the lower urinary tract, defecatory dysfunction, pelvic pain and painful intercourse. Symptoms of PFD are not life threatening but can have a life altering effect on women. The fear of leaking urine or stool can lead to increasing anxiety and sometimes social isolation and depression (Bezerra et al., 2014). Some women are hesitant to exercise, travel or even engage in intimate relationships. Many consider these symptoms a normal part of aging, and believe the only available treatment is medication or surgery (Townsend, Matthews, Whitehead, \& Grodstein, 2013). This is just one of many reasons why incontinence symptoms often go unreported. In addition, women are often embarrassed to discuss incontinence and prolapse with their health care provider as these conditions can take a back seat to other more important health problems such as heart disease and diabetes. Symptoms of PFD are considered life altering, not life threatening and if the health care provider does not have adequate time to address them during a routine office visit, they often go undiagnosed and untreated. The prevalence and economic burden of PFD is high and continues to increase annually. Challenges exist in measuring the exact effect of these symptoms due to variability in definition and lack of symptom report by patients (Nygaard et al., 2008).

Normal function of the pelvic floor musculature is a critical component in maintaining pelvic stability, pelvic organ support and normal function of the female 
pelvic organs. Voluntary control of this muscle group is essential to allow for defecation, micturition, parturition, sexual function, urinary and fecal continence. High tone pelvic floor dysfunction (HTPFD) is a neuromuscular disorder of the pelvic floor that contributes to symptoms of PFD in women such as urinary and fecal incontinence, voiding dysfunction, constipation of obstructed defecation, sexual dysfunction and pain syndromes. HTPFD can lead to an inability to relax the pelvic floor muscles, often resulting in symptoms of PFD in women. Because HTPFD is often overlooked in clinical practice and because it contributes to costly conditions such as urinary incontinence, constipation and pelvic pain, it is important for the health care community to focus on heightening clinician awareness of the condition, standardizing pelvic floor terminology and pelvic muscle exam and educating providers about available treatments. Because a comprehensive review of the literature on symptoms associated with PFD would be overwhelming and because HTPFD is often goes unrecognized as a cause of PFD, the researcher chose to conduct a review of the literature on HTPFD, which is presented in manuscript form in chapter two.

Establishing ambulatory rates for patient care associated with PFD is difficult, commonly relying on large national databases. It is estimated that future demands for incontinence and prolapse care will increase significantly based on ambulatory care projections. Estimates of direct costs of pelvic organ prolapse and stress urinary incontinence surgery exceed one billion dollars and costs for ambulatory care related to PFD in 2006 exceeded \$410 million (Subak et al., 2001; Sung, Washington \& Raker, 2010). 
Pelvic floor disorders often coexist and it is estimated that $23.7 \%$ of women have one or more pelvic floor disorders (Nygaard et al., 2008). As the population ages, health care utilization for PFD is predicted to grow. Wu and colleagues (2010) used US Census Bureau population projections to estimate the total number of women who will undergo surgery for pelvic organ prolapse from 2010 to 2050 and determined that this number is expected to increase by $48.2 \%$ over these four decades.

The limitation of studies on health care utilization is that some women with PFD do not seek care. In a population-based sample of women 40 years or older, the prevalence of UI was $41 \%$; but only $25 \%$ of symptomatic women sought care, $23 \%$ received some care, and $12 \%$ received subspecialty care (Minassian et al., 2012). In a community-based Internet survey of women older than 45 years, 19\% reported accidental bowel leakage but only 29\% of those had sought care (Brown, Wexner, \& Lukacz, 2013). Thus, the incidence of care seeking provides an underestimate of the public health burden of PFD among women in the United States.

Traditional management of PFD in women has followed a clinically compartmentalized and fragmented approach, potentially failing to address multicompartmental symptomology resulting in incomplete resolution of the problem. Women with symptoms PFD often consult with many different health care providers, increasing the potential for duplication and delay in treatment. Multiple referrals can result in increased cost of care and decreased patient satisfaction. Because coexisting pelvic floor disorders are common, evaluation and management of all pelvic floor symptoms by a health care provider specializing in the treatment of PFD could improve overall outcomes for women. APRNs in a urogynecology clinic are uniquely positioned 
to provide comprehensive care to women with urinary, defecatory and pelvic pain complaints. Ongoing research is needed to advance the science of comprehensive nonsurgical management of symptoms of pelvic floor dysfunction by an APRN, resulting in improved QOL for women with these life altering symptoms.

\section{Prior Research}

A retrospective review was conducted between 2009 and 2012 in an academic outpatient practice in Mid Missouri of 728 women who underwent comprehensive pelvic floor rehabilitation by an APRN. A conglomeration of PFMT, biofeedback, behavior modification, EGS, incontinence devices and various indicated pharmacotherapies revealed a mean symptom improvement of $80-85 \%$ in urinary, defecatory and pelvic pain symptoms (Starr et al., 2013). This is the largest PFD nonsurgical data set published to date. Treatment success was thought to be a result of APRNs providing the therapy as they are equipped to address a diversity of pelvic floor health needs that could not be immediately addressed by a physical therapist or physiologist who also provide outpatient care to women with symptoms of PFD. For example, the patients with urogenital atrophy were prescribed vaginal estrogen, patients with pelvic floor muscle spasm were prescribed muscle relaxants, and patients with pelvic organ prolapse were fitted with pessaries. Although anti-muscarinic medications could be prescribed, this was rarely required. Additionally, the APRNs were trained to administer PFMT with biofeedback, as well as intravaginal EGS. The ability to provide this level of care was a likely contributor to the overall success of therapy (Starr et al., 2013). 
However, scientifically it is difficult to determine why this program was such a success. One possibility is regular health professional contact, accountability, and oversight of the patients. In two recent Cochrane reviews of the treatment of urinary incontinence, a pattern emerged in which women receiving more health professional contact were more likely to report improvement compared to women doing with little or no supervision (Hay-Smith et al., 2012; Herderschee, Hay-Smith, Herbison, Roovers, \& Heineman, 2011). It is unclear whether this improvement is related to the facilitation of patient compliance with various therapeutic modalities, placebo effect from the perception of higher quality care or a desire of patients to please their caregivers by reporting symptom improvement. Regardless of the mechanism, patient satisfaction scores reported for this service through a national patient satisfaction survey (PressGaney) were consistently the highest in this academic system, often approaching 97\% (Starr et al., 2013).

The APRNs in this retrospective review gave each patient a clear expectation regarding potential outcome of treatment, taking into consideration their main complaints, physical examination findings, medical history, cognitive ability, and even financial and transportation options to achieve the best outcome. They addressed comorbidities and their effect on success such as morbid obesity, diabetes, smoking and age. Those with urinary, defecatory and pelvic pain symptoms and minimal comorbidities were told they had a chance of achieving at least $80 \%$ improvement with an average of five treatments if they were compliant with exercise and behavior modification. It is worth noting that the number of times patients performed home pelvic 
muscle exercises correlated positively with reported percentage of symptom improvement (at least 4xday, $p=0.005$; at least 2xday. $p=0.03$ ) (Starr et al., 2013).

Although these patients reported excellent clinical improvement in urinary, defecatory and pelvic pain complaints, this study has significant limitations and its findings must be interpreted cautiously. First, it was a retrospective study and is not generalizable due to several limitations including convenience sampling and lack of a comparison group. Only outcomes among subjects who presented for therapy and returned for multiple subsequent visits were analyzed. These individuals likely represent some of the most motivated patients in the population. Additionally, a subjective, nonvalidated instrument was used to measure the primary outcome. "The patient was asked to report "percentage of symptom improvement" in urinary, defecatory and pelvic pain symptoms at each successive treatment session. While internal validity of this measurement is uncertain, this outcome instrument can be considered a form of global rating assessment, which, as a class, provides a robust and reproducible measure. Moreover, the large sample size decreased the impact of outliers on the results. Another limitation was lack of data collection of long-term symptom control. The patients reported significant improvement immediately following treatment but the long-term effects of treatment were not measured.

\section{Current Study}

A more scientific analysis of symptom outcomes and long-term effect of nonsurgical management of symptoms of PFD is needed to advance the science of PFD. With this in mind, this researcher designed a prospective database which was approved 
by the University of Missouri Health Science IRB in 2013. All women who presented to this academic outpatient urogynecology practice for comprehensive pelvic floor rehabilitation by an APRN were asked to enroll. Validated questionnaires including the Pelvic Floor Distress Inventory-20 (PFDI-20) and Pelvic Floor Impact Questionnaire-7 (PFIQ-7) were used to measure changes in QOL. Visual Analog Scales (VAS) were used to track subject perceived symptom improvement. The PFDI-20 and PFIQ-7 questionnaires were completed at initiation and end of treatment and mailed to the subjects at six months and one year to determine long-term treatment effect on QOL. The subjects also completed the VAS at each successive treatment session, six and twelve months to track individual changes in urinary, defecatory and pelvic pain complaints. To date, 428 women have been enrolled. The second manuscript, presented in chapter three is a secondary analysis of the data collected for this review. 


\title{
CHAPTER TWO
}

Manuscript: High Tone Pelvic Floor Muscle Dysfunction: A Review of the Literature

\section{Title}

High Tone Pelvic Floor Muscle Dysfunction: A Review

\begin{abstract}
High tone pelvic floor dysfunction (HTPFD) can be a contributing factor to pelvic floor dysfunction (PFD) and is often overlooked when assessing and treating women with pelvic floor symptoms. A comprehensive literature search was completed in October 2016 and included specific key words such as pelvic floor dysfunction, pelvic pain, rectal pain, and dyspareunia. Literature from PubMed, CINAHL and MEDLINE databases published between 1900 and 2015 was searched for relevant research and information. The search strategy also included a manual review of all relevant articles for further references. Only search results with English language abstracts were reviewed. A total of 256 potentially relevant studies were initially identified. After abstract review, 102 manuscripts were recognized as pertinent. Following review of the manuscripts, 45 articles and two systematic reviews were identified as pertinent. This manuscript will briefly review the anatomy, symptomology, associated conditions and physical evaluation of HTPFD in women with a more comprehensive review of the literature of the currently accepted treatment modalities.
\end{abstract}




\section{Introduction}

High tone pelvic floor dysfunction (HTPFD) is a neuromuscular disorder of the pelvic floor that contributes to a variety of pathological conditions in women such as urinary and fecal incontinence, voiding dysfunction, constipation of obstructed defecation, sexual dysfunction and pain syndromes. The prevalence of the syndrome in the general population is estimated at $6.6 \%$, and is thought to affect more than 10 million women in the United States alone. This disorder can present as pelvic pain, dyspareunia, rectal pain, chronic constipation, low back pain, vaginal and vulvar pain, urinary urgency/frequency, incontinence, hematuria and voiding dysfunction. As a result of the various presenting symptoms, women with HTPFD are seen by a variety of health care providers including primary care providers, obstetrician-gynecologists, urogynecologists, urologists, colorectal surgeons, orthopedic surgeons, chiropractors, pain management specialists, physical therapists, psychotherapists and others. Because the symptoms are vague, and the index for suspicion on the part of the health care provider is low, the diagnosis is frequently missed, and the patient is usually seen by several providers without relief. The purpose of this manuscript is to briefly discuss the anatomy, symptomology, associated conditions and physical evaluation of HTPFD in women with a more comprehensive review of the literature of the currently accepted treatment modalities. Heightened awareness of this condition can contribute to improved assessment and diagnostic skills on the part of the provider resulting in more expedient treatment and relief for the patient. 


\begin{abstract}
Anatomy
The pelvic diaphragm consists of the levator ani and coccygeus muscles along with their superior and inferior layers of fasciae. The levator ani are a group of striated muscles that includes the puborectalis, pubococcygeus and ileoccoccygeus. The coccygeus, piriformis and obturator internus muscles also contribute to the pelvic floor (Andromanakos, Kouraklis, \& Alkiviadis, 2011). The pelvic floor muscles contract and relax, allowing for defecation, micturition, parturition, sexual function, urinary and fecal continence. These muscles provide a critical component of pelvic stability and pelvic organ support. The pelvic floor musculature has two components: the viscoelastic component, which is independent of nervous activity, and the contractile component, which is caused by activation of motor units. It is possible that abnormalities of both the viscoelastic and the contractile component may contribute to the abnormality in pelvic floor muscle tension (Wehbe, Whitmore \& Kellogg-Spadt, 2010).
\end{abstract}

\title{
Definition
}

HTPFD was first described in the literature by Simpson in 1859, though he referred to it somewhat inaccurately as coccygodynia. This condition is more often reported in the colorectal literature and referred to as multiple entities including spastic piriformis (Thiele, 1937), coccygeus-levator spasm syndrome (Paradis \& Marganoff, 1969), tension myalgia of the pelvic floor (Sinaki et al, 1977), levator syndrome (Grant, Salvati \& Rubin, 1975) and spastic pelvic floor syndrome (Bleijenberg \& Kuijpers, 1987). More recently the urologic and gynecologic literature has referred to it as overactive pelvic floor muscles (Messelink et al., 2005), levator ani spasm/syndrome 
(Hull \& Corton 2009), pelvic floor muscle spasm (Bendana et al., 2009) and high tone pelvic floor muscle dysfunction (Finamore, 2008).

In 1937, Thiele described coccygodynia as an entity characterized by pain to the coccyx associated with levator ani and coccygeus muscle spasm. He noted spastic pelvic floor musculature upon digital rectal exam in 64 of 69 patients with coccygeal pain. He further characterized coccygodynia based on a retrospective review of 324 cases in 1963. These patients reported lower sacral and coccygeal pain often exacerbated by prolonged sitting; however, few reported pain with direct palpation of the coccyx (Thiele, 1937). These symptoms are more consistent with a diagnosis of HTPFD rather than coccygodynia.

The term coccygeus-levator spasm syndrome was used by Paradis and Marganoff in 1969 to describe patients with pelvic floor spasm and rectal pain. Their exam revealed tenderness with palpation of sites adjacent to the coccyx and ischial spine, suggesting ligament, tendon and myofascial involvement, rather than the muscles themselves. Infection and trauma were ruled out as etiological factors in this patient population (Paradis \& Marganoff, 1969).

Grant et al. (1975) used the term levator ani syndrome to describe patients with symptoms of pelvic floor muscle tenderness and spasm. Most reported symptoms of rectal pain/discomfort of unknown etiology. They noted that tenderness upon motion of the coccyx is not an important part of this syndrome. Therefore, the term "coccygodynia" should not be used. The authors also reported that the syndrome affected women more 
than men and occurred most often in the fourth, fifth and sixth decades of life (Grant, Salvati, \& Rubin, 1975).

Tension myalgia of the pelvic floor was a term used by Sinaki et al. (1977) to describe patients with spastic pelvic floor muscles. They reported common symptoms including low back pain (82\%), pelvic pressure (64\%) and increased pain with sitting (88\%). The authors also reported a relationship between habitual contracting of pelvic floor muscles and hypochondriasis (Sinaki, Merritt, \& Stillwell, 1977).

More recently, the International Continence Society defined overactive pelvic floor muscles as a condition in which the pelvic floor muscles do not relax or may even contract when relaxation is functionally needed for example during micturition or defecation. They describe it as a condition based on symptoms such as voiding problems, obstructed defecation or dyspareunia and the absence of voluntary pelvic floor muscle relaxation (Messelink et al., 2005). For the purpose of this review, this condition will be referred to as high tone pelvic floor dysfunction (HTPFD).

\section{Prevalence}

HTPFD is thought to affect more than 10 million women in the United States alone with greater than $50 \%$ between the ages of 30 and 60 years (Andromanakos et al, 2008). Previous studies have found that myofascial pain and HTPFD are present in as many as $87 \%$ of patients with interstitial cystitis (IC) and/or chronic pain syndromes (CPS) (Peters, Carrico, Kalinowski, Ibrahim, \& Diokno, 2007). In the colorectal literature, overactive pelvic floor muscles are referred to as tension myalgia of the pelvic floor and levator ani syndrome with a reported prevalence of approximately $6.6 \%$ of the 
general population (Andromanakos, et al., 2011). Abnormal function of the pelvic floor musculature is seen in an estimated $70 \%$ of women with genitourinary, bowel and sexual disorders (Wehbe, Whitmore, \& Kellogg-Spadt, 2010). The etiology of the disease is thought to be multifactorial and therefore often goes unreported.

\section{Clinical Features}

HTPFD occurs when the muscles are chronically tense or in spasm resulting in loss of ability to contract and relax. This can occur as an entity in and of itself but is more commonly associated with other conditions such as urinary urgency/frequency and incontinence (Abbott, 2009; Clemens et al., 2000), urinary retention (Finamore et al., 2008), painful bladder syndrome, vulvar vestibulitis, irritable bowel syndrome, endometriosis, pelvic pain (Andromanakos et al., 2011), fecal incontinence (Andromanakos et al., 2008) and constipation of obstructed defecation (Thiele, 1963). It can be difficult to discern if the muscle spasm developed first or as a result of any of the aforementioned conditions. Commonly reported urinary symptoms include urinary frequency, a sensation of incomplete bladder emptying, urinary hesitancy, varied force of urinary stream and discomfort with bladder filling (Finamore, 2008). Gynecological symptoms may present as deep dyspareunia, pain with orgasm and pelvic discomfort the day following intercourse (Tu, As-Sanie, \& Steege, 2005). Much of the colorectal literature reports patients presenting with complaints of chronic constipation, pain with defecation, pain with prolonged sitting on a hard surface or a sensation of "sitting on a golf ball” (Oyama et al., 2004). Musculoskeletal symptoms can include low back pain and pain radiating to inner thighs (Tu, et al., 2005). Determining the chronological order 
of symptom onset can be a challenge due to the amount of time that often passes prior to the patient receiving the correct diagnosis.

Events that are considered risk factors leading to chronic tensing of the pelvic floor muscles include pelvic muscle strain from trauma such as childbirth, pelvic surgery, sports injury, bicycle riding, sexual abuse; urinary and fecal incontinence, chronic constipation and inflammation of pelvic organs from conditions such as interstitial cystitis, vaginitis, endometriosis, anal fissures; and finally referred pain from nearby muscles, nerves and viscera (Finamore, 2008). Frequent painful voiding as well as anticipation of genital pain during intercourse can result in pelvic floor muscle guarding that, over time, can lead to sustained shortening and spasm of the muscle (Wehbe et al, 2010).

\begin{abstract}
Assessment
Digital vaginal exam of the pelvic floor muscle bed is commonly used to assess for HTPFD in women. The focus of this exam is the evaluation of the levator ani and obturator internus muscles for spasm. The examiner evaluates for taut muscle bands, nodules within the muscles and pain/tenderness using firm yet gentle pressure (Fitzgerald et al., 2011; Hull \& Corton, 2009). Examination of the pelvic floor muscles is performed with the patient in a lithotomy position while the examiner pictures the vagina on the face of a clock. The examiner places a gloved index finger one inch or to the first knuckle inside the distal vagina. The pubococcygeus muscle can be felt from 7 to 11 o'clock on the left and 1 to 5 o'clock of the right. This is followed by deeper insertion of the finger into the vagina with the palpation of the iliococcygeus muscle from the 4 to 8 o'clock position. Evaluation of the obturator internus muscle can then be palpated at the 10 and 2
\end{abstract}


o'clock position. Patients with tenderness on palpation of any of these trigger points are highly likely to have a diagnosis of HTPFD (Chiarioni, Nardo, Vantini, Romito, \& Whitehead, 2010; C. M. Fitzgerald et al., 2011). Examination of the pelvic floor needs to be standardized so that clinicians can make reliable clinical decisions across patients and across time not only in the initial diagnosis but also in the evaluation of the patient's response to treatment. A more accurate diagnosis may also lead to more appropriate subgroupings; visceral versus musculoskeletal which could in turn lead to more appropriate management by healthcare providers (Hull \& Corton, 2009).

Assessment of pelvic floor muscle strength is important to determine a woman's ability to isolate, contract and relax the pelvic floor muscles. Chronically tense pelvic floor muscles lose their ability to contract and relax. Once patients with HTPFD learn to isolate these muscles, they can be trained to relax them. The quantification of a contraction is problematic and to date there is no validated scale to quantify contractions of the pelvic floor muscles. A correct contraction can be observed clinically (Kegel, 1948), by ultrasound (Beco, Sulu, \& Schaaps, 1987; Dietz, Jarvis, \& Vancaillie, 2002; Jarvis, Abbott, Lenart, Steensma, \& Vancaillie, 2004) or with dynamic magnetic resonance imaging (Stoker, Halligan, \& Bartram, 2001). The Oxford scale is used most frequently, but inter-observer variability has been reported to be high. Although vaginal assessment of pelvic floor muscle strength may be internally consistent, reliability and reproducibility between examiners varies (Bø \& Finckenhagen, 2001). Objective measurements such as perineometry, perineal ultrasound and EMG are consistent in providing evidence of contraction but none are able to assess true strength (Rogalski, Kellogg-Spadt, Hoffmann, Fariello, \& Whitmore, 2010). The Pelvic Floor Clinical 
Assessment Group of the International Continence Society is an international group of interdisciplinary experts with an interest in the standardization of terminology of pelvic floor muscle function and dysfunction. This world-renowned medical committee recommends the following method of examining pelvic floor muscle strength in women: The patient is placed in a supine position with hips and knees flexed. One gloved, lubricated finger is introduced into the vagina and the patient is asked to contract the muscles around the examiners finger. Instructing the patient to "lift" and "squeeze" may be necessary if the patient is having difficulty isolating the pelvic floor muscles. There is no gold standard scale to refer to when quantifying pelvic floor strength, therefore this group does not recommend anything more than the simplest classification of absent, weak, normal or strong (Messelink et al., 2005).

\section{Treatment}

The aim of treatment for HTPFD is to relax the pelvic floor musculature and restore proper functioning of the pelvic floor organs. Currently accepted therapies include pelvic floor muscle massage to elongate musculature and relieve pain, benzodiazepines for their antispasmotic activity in muscle hypertonis and pelvic floor therapy/biofeedback with or without electrogalvanic stimulation (Tu, et al., 2005). Trigger point injections have also proven beneficial in patients with chronically contracted pelvic floor musculature.

\section{Manual Therapy}

Direct pelvic muscle massage is well documented in the literature as an effective treatment for HTPFD. This is often performed by a physical therapist specializing in the 
treatment of PFD. The aim of direct massage of the pelvic floor is to elongate shortened muscles and decrease high tone spasm (M. P. Fitzgerald et al., 2009; Lukban \& Whitmore, 2002). Thiele reported a case series of 31 patients with pelvic muscle pain who underwent a series of direct transrectal massage of the pelvic floor muscles. Nineteen subjects $(61.3 \%)$ reported complete resolution of their pain and $17(35.5 \%)$ showed improvement after multiple sessions of therapy (Thiele, 1937). Thiele combined this data with eight other proctologists using the same technique and reported $93.7 \%$ improvement in a total of 80 participants (Thiele, 1963).

Manual therapy of the pelvic floor in patients with genitourinary disorders has also proven to be successful. Weiss used a transvaginal or transrectal approach to 10 patients with interstitial cystitis (IC) and 42 patients with urinary urgency/frequency. The treatment included pelvic floor muscle compression, stretching and right angle strumming with the simultaneous use of external myofascial release or application of heat to facilitate greater muscle relaxation. Seventy percent of the IC patients and $83 \%$ of the urgency/frequency group reported greater than 50\% improvement in their symptoms as determined by patient-completed questionnaires (Weiss, 2001). An unspecified number of these patients also had trigger points injected as part of their therapy. Whether the impact of the treatment favored the pain symptoms as opposed to urologic function was not made clear.

Oyama et al., (2004) evaluated the effectiveness of the modified Thiele's massage in 21 women with IC. The study participants received weekly transvaginal massage for six weeks with symptom evaluation before, immediately after, and 4.5 months following treatment. The results indicated statistically significant improvement in the mean 
symptom and problem indices of the O'Leary - Sant Questionnaire and the SF-12 Quality-of-Life scale. The researchers reported improvement in irritative voiding symptoms as well as a decrease in pelvic floor muscle tone (Oyama, et al., 2004).

A recent randomized clinical trial was designed to compare two methods of manual therapy in patients with urological chronic pelvic pain syndromes including chronic prostatitis/chronic pelvic pain syndrome or IC. Twenty four patients were randomized to global therapeutic massage, 23 to myofascial physical therapy and $94 \%$ completed the study. The overall response rate of $57 \%$ in the myofascial physical therapy group was significantly higher than the global therapeutic group (21\%) suggesting myofascial therapy is a meaningful treatment option for HTPFD with associated pelvic pain (Fitzgerald, et al., 2009).

\section{Benzodiazepines}

Although muscle relaxants have been suggested to be effective in the treatment of muscle spasm, only two studies have evaluated the use of diazepam for the relief of pain in patients with HTPFD. McGivney and Cleveland (1965) reported that oral administration of diazepam for an average period of 11 weeks produced marked relief of symptoms of pelvic pain. Of the 64 participants, $80 \%$ subjectively reported marked relief, 14\% had minimal relief and 6\% were uncertain (McGivney \& Cleveland, 1965). A 2010 retrospective chart review evaluating intravaginal diazepam (10 mg suppositories) as adjunctive treatment for dyspareunia related to pelvic muscle spasm showed that 25 of 26 patients reported improvement with suppository use. Pelvic floor muscle tone and pain were assessed by palpation and perineometry. Sexual pain was objectively rated by 
Female Sexual Function Index and the Visual Analog Scale for Pain. The authors concluded that vaginal valium suppositories gave a clinically significant improvement in the treatment of HTPFD compared with the usual treatment regimen alone (Rogalski, et al., 2010).

Crisp et al., (2013) enrolled 21 subjects into a triple-blinded placebo-controlled randomized trial to determine if $10 \mathrm{mg}$ diazepam suppositories improved resting pelvic floor electromyography (EMG) compared with placebo. The researchers discovered no difference in any of the resting vaginal EMG assessments at any time point within subjects or between groups and no differences were noted in any of the validated questionnaires.

\section{Trigger Point Injections}

In addition, trigger point injections into chronically contracted pelvic floor musculature has been shown to be helpful in the relief of pelvic pain. Trigger point injections are typically used as adjuvant therapy to pharmacotherapy, physical therapy and behavioral therapy. Therefore, it is recommended they not be used as first-line treatment, or as monotherapy for chronic pelvic pain. A myriad of medications and techniques may be used for administering injections. The most common are intramuscular infiltration with a local anesthetic such as lidocaine or bupivicaine (Moldwin, R.M. \& Fariello; 2013).

Langford, Udvari, Nagy \& Ghonieum (2007) studied the role of trigger point injections in eighteen women with pelvic floor muscle spasm and chronic pelvic pain of at least six months duration. The trigger points were identified by digital intravaginal palpation of the levator ani muscles and mixture of $0.25 \%$ bupivacaine, $2 \%$ lidocaine, and 
triamcinolone was injected. Thirteen of eighteen women improved after the first trigger point injection with a mean follow up of three months, resulting in a comprehensive success rate of $72 \%$; six of 18 women (33\%) reported complete resolution of their pain.

Fouad, Chen, Pettit, \& Micallef (2015) conducted a retrospective review of 75 patients who underwent outpatient transvaginal trigger point injections for HTPFD from 2007-2015. VAS scores were recorded before and 1-2 weeks after treatment.

Improvement was noted via VAS in $63 \%$ of patients $(\mathrm{p}<.0001)$. Twenty seven percent of patients underwent repeat trigger point injection and 16\% needed Botox injection.

A number of studies have been published revealing the effectiveness of trigger point injections of onabotulinumtoxinA (BoNTA) resulting in muscle paralysis and subsequent relief of pelvic pain due to HTPFD (Abbott, Jarvis, Lyons, Thomson, \& Vancaille, 2006; Jarvis, et al., 2004; Rao, Paulson, Mata, \& Zimmerman, 2009; Romito et al., 2004; Thomson, Jarvis, Lenart, Abbott, \& Vancaillie, 2005). Urinary incontinence related to neurogenic detrusor overactivity is currently the only approved indication for BoNTA into the female pelvis. Other supported off-label uses include: idiopathic detrusor overactivity, interstitial cystitis/bladder pain syndrome, detrusor sphincter dyssynergia, HTPFD, anal fissure, anismus, and functional anal pain (El-Khawand, Wehbe, \& Whitmore, 2013). BoNTA may effectively and safely be used in many conditions of the female pelvis. More high quality research is needed to better clarify its role in the therapeutic algorithm for those indications.

Adelowo, Hacker, Shapiro, Modest, \& Elkadry. (2013) published a retrospective cohort study of 31 women who underwent intralevator Botox injection between 2005 and 2010 for refractory myofascial pelvic pain. Primary outcomes were self-reported pain on 
palpation and symptom improvement. Secondary outcomes included postinjection complications and a second injection. The researchers concluded that intralevator injection of Botox demonstrates effectiveness in women with refractory myofascial pelvic pain with few self-limiting adverse effects. However, this study is limited by its retrospective design and lack of validated questionnaires.

Nesbitt-Hawes, Won, Jarvis, Lyons, Vancaillie, \& Abbott, (2013) published a prospective study to report the outcomes of pain and vaginal pressures of successive botulinum toxin type A injections for women with objective HTPFD and a two-year history of pelvic pain. Between 2005 and 2008, 37 women underwent injection of $100 \mathrm{IU}$ of botulinum toxin type A into the levator ani muscles. Outcomes were determined with use of VAS and vaginal pressure measured by vaginal manometry, at $0,4,12$ and 26 weeks from each injection. Twenty six women (70\%) had one injection of BoTNA and $11(30 \%)$ had two or more injections. They reported that both single and repeated injections demonstrated a statistically significant reduction in dyspareunia $(\mathrm{p}=.001)$, non-menstrual pelvic pain $(\mathrm{p}=.04)$, as well as vaginal pressures $(\mathrm{p}=.02)$. No statistically significant difference in dysmenorrhea or dyschesia was observed for either group. The authors concluded that women who have had benefit from a single injection of botulinum toxin type A can be reassured that if symptoms reoccur, repeated injections can be expected to be equally efficacious.

Bertolasi, Frasson, Cappelletti, Vicentini, Bordignon, \& Graziottin, (2013) prospectively recruited 39 women whom failed standard treatment for vaginismus and vulvar vestibular syndrome to investigate whether BoTNA offered symptom improvement. Validated questionnaires were administered and pelvic floor EMG was 
recorded. The primary outcome measures (the possibility of having sexual intercourse, and levator ani EMG hyperactivity) both improved, as did the QOL and sexual functioning scores. When follow-up ended, $63.2 \%$ of the patients completely recovered from vaginismus and vulvar vestibular syndrome, $15.4 \%$ still needed reinjections (censored), and $15.4 \%$ had dropped out.

In one pilot prospective cohort study, BoNTA was injected into the levator ani muscles of twelve women with a two-year history of chronic pelvic pain associated with HTPFD. Median visual analog scale pain scores were significantly improved for dyspareunia and dysmenorrhea. Both QOL and sexual activity scores were markedly improved (Jarvis, et al., 2004). A randomized control trial by Abbot et al., (2006) revealed that BoTNA injections into the pelvic floor muscles of thirty women with chronic pelvic pain had significantly greater improvement in dyspareunia, pelvic pain and pressure than the non-treatment group. Bhide et al., (2015) published a systematic review of the literature up to 2012 on the use of BoNTA in the treatment of pelvic muscle spasm and concluded that although data remained scarce, preliminary results are encouraging.

Morrissey et al., (2015) conducted a prospective pilot study of women with chronic pelvic pain and HTPFD who failed conventional therapy. BoTNA injections were performed from a transperineal approach, using needle electromyography guidance to localize spastic pelvic floor muscles. Data were collected at baseline, 4, 8, 12, and 24 weeks after injections including Visual Analog Scale (VAS) scores for pain and dyspareunia; validated questionnaires for symptoms, QOL, and sexual function; Global Response Assessment scale for pelvic pain; digital examination of PFM for tone and tenderness; and vaginal manometry. Side effects were also recorded. Out of 28 women 
who enrolled in the study, 21 completed the 6-month follow-up and qualified for analysis. Overall, $61.9 \%$ of subjects reported improvement on Global Response Assessment at 4 weeks and $80.9 \%$ at 8,12 , and 24 weeks post injection, compared with baseline. Of the subjects who were sexually active at baseline, 58.8\% (10/17), 68.8\% $(11 / 16), 80 \%(12 / 15)$, and $83.3 \%(15 / 18)$ reported less dyspareunia at 4, 8, 12, and 24 weeks, respectively. Sexual dysfunction as measured by the Female Sexual Distress Scale significantly improved at 8 weeks $(\mathrm{P}=0.005), 12$ weeks $(\mathrm{P}=0.006)$, and 24 weeks $(\mathrm{P}<$ 0.001) compared with baseline. The Short-Form 12 Health Survey (SF-12) showed improved QoL in the physical composite score at all post injections visits $(\mathrm{P}<0.05)$, and in the mental composite score at both 12 and 24 weeks $(P=0.012)$. Vaginal manometry demonstrated significant decrease in resting pressures and in maximum contraction pressures at all follow-up visits $(\mathrm{P}<0.05$ ). Digital assessment of PFM (on a scale from 0 to 4) showed decreased tenderness on all visits ( $\mathrm{P}<0.001)$ compared with baseline. Reported postinjection adverse effects included worsening of the following preexisting conditions: constipation (28.6\%), stress urinary incontinence (4.8\%), fecal incontinence (4.8\%), and new onset stress urinary incontinence (4.8\%).

\section{Electrogalvanic stimulation}

EGS of the pelvic floor musculature has been shown to decrease muscle spasm by fatigue after sustained muscle contraction. This, in addition to motor neuron suppression is believed to be the mechanism of pain relief in patients with pelvic/rectal pain associated with HTPFD (Lukban \& Whitmore, 2002). This method of treatment employs painless, high voltage direct current to the pelvic floor muscles with use of vaginal or anal probe. This method is not to be confused with electrical stimulation via an external 
route which employs low voltage alternating current to facilitate muscle relaxation. EGS for the treatment of HTPFD was first described by Sohn et al., (1982) in a retrospective review of sixty women and twenty men with symptoms of pelvic/rectal pain. The patients were treated with rectal EGS for one hour per day over a period of 3-10 days. Complete resolution of symptoms in $69 \%$ of the patients was reported with no recurrence during 6 to 30 months follow up. In $21 \%$ of the participants, complete resolution of pain was reported with a return of symptoms at follow up. The authors concluded that because this therapy is simple, safe and not associated with significant side effects, it should be used as a primary modality of therapy for those with a diagnosis of HTPFD (Sohn, Weinstein, \& Robbins, 1982).

A similar study was conducted by Nicosia and Abcarian (1985) in the treatment of 32 women and 13 men who underwent twenty minutes of intra-anal electrogalvanic stimulation therapy every other day for an average of five treatments. Total relief of pelvic/rectal pain was reported by $80 \%$ of the participants. The authors concluded that electrical stimulation is the treatment of choice for HTPFD because it can be standardized, is well tolerated and is over $90 \%$ effective (Nicosia \& Abcarian, 1985).

Oliver et al. (1985) reviewed the records of ninety patients with HTPFD who underwent a total of three rectal EGS treatments. All sessions lasted 60 minutes within a period of ten days. Prior to beginning EGS, conservative treatments were tried and failure of the conservative regimen was part of the inclusion criteria of this study (Oliver, Rubin, Salvati, \& Eisenstat, 1985). Relief or improvement of symptoms was reported by $77 \%$ of these patients. Likewise, Morris and Newton (1987) published a retrospective review of 23 women and five men with diagnosis of HTPFD who underwent rectal EGS therapy. 
"Relief" of pain was reported in $75 \%$ of the participants with an average of six treatments. This study was unique in that it used a VAS to quantitatively measure the outcomes (Morris \& Newton, 1987).

Intra-anal EGS was performed on 20 patients with a diagnosis of HTPFD by Billingham et al., (1987). The participants underwent a series of one to twelve 15-60 minute treatments with a reported $60 \%$ improvement immediately following therapy. Ongoing improvement several weeks to several months after treatment was reported by $25 \%$ of the participants. There were eleven females and nine males in this study ranging in age from 32 to 88 years. All had failed previous treatment for symptoms of rectal pain (Billingham, Isler, Friend, \& Hostetler, 1987).

Patients undergoing intra-anal EGS stimulation for a diagnosis of HTPFD between 1985 and 1991 were studied by Hull, Milsom and Church et al. (1993) to determine the long term benefits of this treatment modality. Each of the fifty two patients underwent three treatments every other day with additional treatments performed per patient request. The authors obtained follow up data via phone call $(n=31)$ or patient medical record $(n=11)$. Of these patients $27 \%$ of the chart follow ups reported treatment benefit seven weeks after completion of therapy and $16 \%$ of those undergoing phone interview reported ongoing improvement after three years (Hull et al., 1993).

Fitzwater, Kuehl \& Schrier (2003) conducted a retrospective cohort study of 50 women treated with vaginal EGS for HTPFD. Demographic data was collected including, mean age, parity, education, marital status and race. Most subjects underwent three or less treatments with $68 \%$ reporting improvement in symptoms at completion of therapy. 
Using survival analysis, the authors reported $51 \%$ of patients had persistent improvement thirty weeks after treatment. They determined that there was no significant difference in age, race, parity or education in patients reporting a sustained benefit from treatment and those reporting no benefit (Fitzwater et al., 2003).

\section{Biofeedback and EGS Combined}

EGS combined with biofeedback has been shown to be effective in the treatment of HTPFD but is poorly described in the literature. Soe, Choe, Lee \& Kim (2005) reported improvement in symptoms of vaginismus in twelve women who underwent transvaginal EGS and biofeedback. All twelve women were able to achieve satisfactory vaginal intercourse following eight weeks of therapy. Bendana et al. (2009) conducted a retrospective review of 52 women who presented to a urology clinic with symptoms of urinary urgency/frequency associated with HTPFD. The women were treated with six weekly one hour sessions undergoing biofeedback and vaginal EGS. Symptom improvement of $64.5 \%$ was reported immediately following treatment and at three months. Symptom severity demonstrated statistically significant improvement and effect on daily life (Bendana et al., 2009).

Starr et al. (2013) published a retrospective review of 728 women who underwent biofeedback and EGS with a reported mean improvement of $80 \%$ in bladder, bowel and pelvic pain complaints. However, these researchers did not report the percentage of these women with HTPFD. 


\section{Treatment Limitations/Recommendations}

There are significant limitations in the existing literature regarding treatment of HTPFD leaving little evidence to guide the clinician. The vast majority of the aforementioned studies failed to use a control group, possibly overestimating their effectiveness and relegating their scientific use only to hypothesis generation for future studies. Also, many used subjective outcomes which may not represent meaningful outcomes in different population. Most failed to use quantitative outcome measures such as quality of life questionnaires and visual analog pain scales, ignoring the need for careful assessment of clinical outcomes. Furthermore, the majority of the studies combined men and women together in analysis, ignoring the relevance of gender specific causes for HTPFD.

Treatment recommendation for patients with HTPFD can depend on several factors including availability of treatment, cost and patient motivation/willingness to take an active role in their care. A therapy that is simple, safe and not associated with significant side effects should be used as a primary modality such as pelvic muscle massage or EGS with or without biofeedback. In order to achieve a successful outcome, both treatments require an average of 6-8 sessions with a therapist and a willingness to perform simple exercises every day. Availability of either treatment may be a challenge as these therapies are often not performed in smaller communities. Trigger point injections have proven useful and should be considered if less invasive therapies fail. Vaginal diazepam suppositories can be used as an adjunct treatment or when the patient does not have access to other modalities. Cost should always be considered as reimbursement varies depending on the patient insurance plan. Finally, each patient 
should be given the options for treatment and allowed to take part in the treatment decision.

\section{Discussion}

Normal function of the pelvic floor musculature is a critical component in maintaining pelvic stability, pelvic organ support and normal function of the female pelvic organs. Voluntary control of this muscle group is essential to allow for defecation, micturition, parturition, sexual function, urinary and fecal continence. HTPFD can lead to an inability to relax the pelvic floor muscles, often resulting in dysfunction of more than one organ system. Because HTPFD is often overlooked in clinical practice and because it contributes to costly conditions such as urinary incontinence, constipation and pelvic pain, it is important for the health care community to focus on heightening clinician awareness of the condition, standardizing pelvic floor terminology and pelvic muscle exam and educating providers about available treatments.

HTPFD is referred to as multiple entities in the literature and no standardized terminology of pelvic floor muscle dysfunction or diagnostic exam was found upon completion of this review. Basic studies on the different aspects of the pelvic floor muscles were limited due in part to the difficulty in defining the different aspects of this muscle group and their function. Even if they were defined, they could not be easily measured and if they were measurable there is no agreement as to normal values.

Including HTPFD in the differential diagnosis is important when assessing a patient presenting with symptoms of PFD. Common conditions such as constipation, voiding dysfunction, urinary incontinence and pelvic pain can be associated with this 
condition and are commonly seen in family practice settings as well as gerontology, gastroenterology, colorectal, urology and gynecology. Publication of review articles in associated professional journals will increase clinician awareness of this condition and potentially lead to more accurate and timely diagnosis and treatment, resulting in improved patient outcomes and saving of health care dollars.

Standardization of pelvic floor muscle assessment is necessary to provide the examiner with information regarding normal or abnormal findings that might suggest a muscular basis for the patient's symptoms. This will allow the provider to make reliable decisions across patients and across time not only with the initial diagnosis but also in evaluation of the treatment response. Professional organizations such as the International Continence Society and International Urogynecology meet annually to discuss such issues and progress is being made in standardization of terminology and patient exam.

Clearly increased scientific rigor is needed to guide management of HTPFD and establishment of diagnostic criteria should be a priority. Further randomized controlled studies are necessary to determine comprehensive exam methods, effective treatment modalities and evaluation of treatment response. Validated quality of life questionnaires are recommended to quantitatively measure outcomes. Publication of case series and individual case studies would be useful to quickly bring this condition to the attention of clinicians who may otherwise not include HTPFD as a differential diagnosis. Priority should be given to the aforementioned recommendations so that millions of women can be quickly diagnosed and treated, resulting in saving of health care dollars and improved patient outcomes. 


\section{References}

Abbott, J. A., Jarvis, S. K., Lyons, S. D., Thomson, A., \& Vancaille, T. G. (2006). Botulinum toxin type A for chronic pain and pelvic floor spasm in women: a randomized controlled trial. Obstetrics and Gynecology, 108(4), 915-923. doi: 10.1097/01.AOG.0000237100.29870.cc

Adelowo, A., Hacker, M., Shapiro, A., Modest, A., Elkadry, E. (2013). Botulinum toxin type A (BOTOX) for refractory myofascial pelvic pain. Female Pelvic Medicine \& Reconstructive Surgery, 19(5), 288-292. doi: 10.1097/SPV.0b013e3182989fd8. PMID: 23982578

Andromanakos, N. P., Kouraklis, G., \& Alkiviadis, K. (2011). Chronic perineal pain: Current pathophysiological aspects, diagnostic approaches and treatment. European Journal of Gastroenterology and Hepatology, 23(1), 2-7. doi: 10.1097/MEG.0b013e32834164f6

Beco, J., Sulu, M., \& Schaaps, J. P. (1987). A new approach to urinary continence disorders in women: urodynamic ultrasound examination by the vaginal route. Journal de Gynecologic, Obstetrique et Biologic de la Reproduction, 16(987998).

Bendana, E. E., Belarmino, J. M., Dinh, J. H., Cook, C. L., Murray, B. P., Feustel, P. J., \& De, E. J. (2009). Efficacy of transvaginal biofeedback and electrical stimulation in women with urinary urgency and frequency and associated pelvic floor muscle spasm. Urologic Nursing, 29(3), 171-176.

Bertolasi, L., Frasson, E., Cappelletti, J.Y., Vicentini, S., Bordignon, M., Graziottin, A. (2009). Botulinum neurotoxin type A injections for vaginismus secondary to vulvar vestibulitis syndrome. Obstetrics \& Gynecology, 114(5), 1008-1016. doi: 10.1097/AOG.0b013e3181bb0dbb. PMID: 20168100

Bhide, A.A. (2013). Botulinum neurotoxin type A injection of the pelvic floor muscle in pain due to spasticity: a review of the current literature. International Urogynecology Journal, 24: 1429-1434.

Billingham, R. P., Isler, J. T., Friend, W. G., \& Hostetler, J. (1987). Treatment of Levator Syndrome Using High Voltage Electrogalvanic Stimulation. Diseases of the Colon and Rectum, 30, 584-587.

Bleijenberg, G., \& Kuijpers, H. C. (1987). Treatment of the spastic pelvic floor syndrome with biofeedback. Diseases of the Colon and Rectum, 30(2), 108-111.

B $\varnothing$, K., \& Finckenhagen, H. B. (2001). Vaginal palpation of pelvic floor muscle strength: Inter-test reproducibility and comparison between palpation and vaginal squeeze pressure. Acta Obstetricia et Gynecologica Scandinavica, 80(10), 883-887. doi: 10.1034/j.1600-0412.2001.801003.x 
Chiarioni, G., Nardo, A., Vantini, I., Romito, A., \& Whitehead, W. E. (2010). Biofeedback Is Superior to Electrogalvanic Stimulation and Massage for Treatment of Levator Ani Syndrome. Gastroenterology, 138(4), 1321-1329. doi: 10.1053/j.gastro.2009.12.040

Crisp, C.C., Vaccaro, C.M., Estanol, M.V., Oakley, S.H., Kleeman, S.D., Fellner, A.N., Pauls, R.N. (2013). Intra-vaginal diazepam for high-tone pelvic floor dysfunction: a randomized placebo-controlled trial. International Urogynecololgy Journal, 24(11), 1915-23. doi: 10.1007/s00192-013-2108-9.PMID: 23681047

Dietz, H. P., Jarvis, S. K., \& Vancaillie, T. G. (2002). The assessment of levator muscle strength: a validation of three ultrasound techniques. International Urogynecology Journal, 13, 156-159.

El-Khawand, D., Wehbe, S., Whitmore, K. (2013). Botulinum toxin for conditions of the female pelvis. International Urogynecology Journal, 24(7), 1073-1081. doi: 10.1007/s00192-012-2035-1. Review. PMID: 23344218

Finamore, P. S., Goldstein, Howard B., Whitmore, Kristene E. (2008). Pelvic Floor Muscle Dysfunction: A Review. Pelvic Medicine and Surgery, 14(6), 5-22. doi: 10.1097/SPV.Obo13e3181907870

Fitzgerald, C. M., Neville, C. E., Mallinson, T., Badillo, S. A., Hynes, C. K., \& Tu, F. F. (2011). Pelvic floor muscle examination in female chronic pelvic pain. Journal of Reproductive Medicine, 56(3-4), 117-122.

Fitzgerald, M. P., Anderson, R. U., Potts, J., Payne, C. K., Peters, K. M., Clemens, J. Q., . . . Nyberg, L. M. (2009). Randomized Multicenter Feasibility Trial of Myofascial Physical Therapy for the Treatment of Urological Chronic Pelvic Pain Syndromes. The Journal of Urology, 182(2), 570-580. doi: 10.1016/j.juro.2009.04.022

Fouad, L.S., Chen, A.H., Pettit, P.D., Micallef, A. (2015). Transvaginal Trigger Point Injections for Pelvic Floor Myofascial Spasm: A Retrospective Review of Pain Assessment and Development of a Treatment Algorithm. Journal of Minimally Invasive Gynecology, 22(6S), S247-S248. doi: 10.1016/j.jmig.2015.08.864. PMID: 27679176

Grant, S. R., Salvati, E. P., \& Rubin, R. J. (1975). Levator syndrome: an analysis of 316 cases. Diseases of the Colon and Rectum, 18(2), 161-163.

Hull, T. L., Milsom, J. W., Church, J., Oakley, J., Lavery, I., \& Fazio, V. (1993). Electrogalvanic stimulation for levator syndrome: How effective is it in the long term? Diseases of the Colon and Rectum, 36(8), 731-733. doi: $10.1007 / \mathrm{bf} 02048360$ 
Jarvis, S. K., Abbott, J. A., Lenart, M. B., Steensma, A., \& Vancaillie, T. G. (2004). Pilot study of botulinum toxin type A in the treatment of chronic pelvic pain associated with spasm of the levator ani muscles. Australia New Zealand Journal of Obstetrics and Gynaecology, 44(1), 46-50. doi: 10.1111/j.1479828X.2004.00163.x

Kegel, A. H. (1948). Progressive resistance exercise in the functional restoration of the perineal muscles. American Journal of Obstetrics and Gynecology, 56, 238-249.

Langford, C. F., Udvari Nagy, S., \& Ghoniem, G. M. (2007). Levator ani trigger point injections: An underutilized treatment for chronic pelvic pain. Neurourology Urodynamics, 26(1), 59-62. doi: 10.1002/nau.20393

Lukban, J. C., \& Whitmore, K. E. (2002). Pelvic floor muscle re-education treatment of the overactive bladder and painful bladder syndrome. Clinical Obstetrics and Gynecology, 45(1), 273-285. doi: 10.1097/00003081-200203000-00028

McGivney, J. Q., \& Cleveland, B. R. (1965). The Levator Syndrome and Its Treatment. Southern Medical Journal, 58, 505-510.

Messelink, B., Benson, T., Berghmans, B., Bo, K., Corcos, J., Fowler, C., Van Kerrebroeck, P. (2005). Standardization of terminology of pelvic floor muscle function and dysfunction: report from the pelvic floor clinical assessment group of the International Continence Society. Neurourology Urodynamics, 24(4), 374380. doi: 10.1002/nau.20144

Moldwin, R.M. \& Fariello, J.Y. (2013). Myofascial Trigger Points of the Pelvic Floor: Associations with Urological Pain Syndromes and Treatment Strategies Including Injection Therapy. Current Urology Report, 14, 409. doi:10.1007/s11934-0130360-7

Morris, L., \& Newton, R. A. (1987). Use of High Voltage Pulsed Galvanic Stimulation for Patients with Levator Ani Syndrome. Physical Therapy, 67(10), 1522-1525.

Morrissey, D.1., El-Khawand, D., Ginzburg, N., Wehbe, S., O'Hare, P., Whitmore, K. (2015). Botulinum Toxin A Injections Into Pelvic Floor Muscles Under Electromyographic Guidance for Women With Refractory High-Tone Pelvic Floor Dysfunction: A 6-Month Prospective Pilot Study. Female Pelvic Medicine \& Reconstructive Surgery, 21(5):277-282. doi: 10.1097/SPV.0000000000000177.

Nesbitt-Hawes, E.M., Won, H., Jarvis, S.K., Lyons, S.D., Vancaillie, T.G., Abbott, J.A. (2012). Improvement in pelvic pain with botulinum toxin type A - Single vs. repeat injections. Toxicon, 63:83-87. doi: 10.1016/j.toxicon.2012.11.018. PMID: 23220489 
Nicosia, J. F., \& Abcarian, H. (1985). Levator syndrome. A treatment that works. Diseases of the Colon and Rectum, 28(6), 406-408.

Oliver, G. C., Rubin, R. J., Salvati, E. P., \& Eisenstat, T. E. (1985). Electrogalvanic stimulation in the treatment of levator syndrome. Diseases of the Colon and Rectum, 28(9), 662-663.

Oyama, I. A., Rejba, A., Lukban, J. C., Fletcher, E., Kellogg-Spadt, S., Holzberg, A. S., \& Whitmore, K. E. (2004). Modified Thiele massage as therapeutic intervention for female patients with interstitial cystitis and high-tone pelvic floor dysfunction. Urology, 64(5), 862-865. doi: 10.1016/j.urology.2004.06.065

Paradis, H., \& Marganoff, H. (1969). Rectal pain of extrarectal origin. Diseaes of the Colon and Rectum, 12(4), 306-312.

Peters, K. M., Carrico, D. J., Kalinowski, S. E., Ibrahim, I. A., \& Diokno, A. C. (2007). Prevalence of Pelvic Floor Dysfunction in Patients with Interstitial Cystitis. Urology, 70(1), 16-18. doi: 10.1016/j.urology.2007.02.067

Rao, S. S., Paulson, J., Mata, M., \& Zimmerman, B. (2009). Clinical trial: effects of botulinum toxin on Levator ani syndrome--a double-blind, placebo-controlled study. Alimentary Pharmacology \& Therapeutics, 29(9), 985-991. doi: 10.1111/j.1365-2036.2009.03964.x

Rogalski, M., Kellogg-Spadt, S., Hoffmann, A., Fariello, J., \& Whitmore, K. (2010). Retrospective chart review of vaginal diazepam suppository use in high-tone pelvic floor dysfunction. International Urogynecology Journal, 21(7), 895-899. doi: 10.1007/s00192-009-1075-7

Romito, S., Bottanelli, M., Pellegrini, M., Vicentini, S., Rizzuto, N., \& Bertolasi, L. (2004). Botulinum toxin for the treatment of genital pain syndromes. Gynecology Obstetrics Investigation, 58(3), 164-167. doi: 10.1159/000079620

Sinaki, M., Merritt, J. L., \& Stillwell, G. K. (1977). Tension myalgia of the pelvic floor. Mayo Clintologyical Proc, 52(11), 717-722.

Sohn, N., Weinstein, M. A., \& Robbins, R. D. (1982). The levator syndrome and its treatment with high-voltage electrogalvanic stimulation. [Case Reports]. American Journal of Surgery, 144(5), 580-582.

Stoker, J., Halligan, S., \& Bartram, C. (2001). Pelvic floor imaging. Radiology, 218, 621641.

Thiele, G. H. (1937). Coccygodynia and pain in the superior gluteal region. Journal of the American Medical Association, 109. 
Thiele, G. H. (1963). Coccygodynia: Cause and Treatment. Dis Colon Rectum, 6, 422436.

Thomson, A. J. M., Jarvis, S. K., Lenart, M., Abbott, J. A., \& Vancaillie, T. G. (2005). The use of botulinum toxin type A (BOTOX®) as treatment for intractable chronic pelvic pain associated with spasm of the levator ani muscles. BJOG: An International Journal of Obstetrics and Gynaecology, 112(2), 247-249. doi: 10.1111/j.1471-0528.2004.00315.x

Tu, F. F., As-Sanie, S., \& Steege, J. F. (2005). Musculoskeletal causes of chronic pelvic pain: a systematic review of existing therapies: part II. Obstetrical and Gynecolgical Survey, 60(7), 474-483.

Wehbe, S. A., Whitmore, K., \& Kellogg-Spadt, S. (2010). Urogenital complaints and female sexual dysfunction (part 1). Journal of Sexual Medicine, 7(5), 1704-1713. doi: 10.1111/j.1743-6109.2010.01769.x

Weiss, J. M. (2001). Pelvic floor myofascial trigger points: Manual therapy for interstitial cystitis and the urgency-frequency syndrome. Journal of Urology, 166(6), 22262231 . 


\section{CHAPTER THREE}

\section{Methods/proposal}

\section{PROPOSED STUDY}

For this proposed study, the researcher will conduct a secondary analysis of a longitudinal data set of 406 women who presented for comprehensive pelvic floor rehabilitation by an APRN for symptoms of pelvic floor dysfunction (PFD). This type of comprehensive treatment analysis is lacking in the literature and to date only retrospective or underpowered studies have been published (Hay-Smith et al., 2015). Analyzing and reporting these data will advance the literature on complex outpatient management of women with symptoms of PFD. In addition, analyzing the demographic data of these women will glean valuable information regarding who is most likely to benefit from this treatment regimen, assisting providers in treatment recommendation.

Data analysis will include the Pelvic Floor Distress Inventory (PFDI-20) and the Pelvic Floor Impact Questionnaire (PFIQ-7) questionnaires administered at baseline, completion of treatment, six months and one year to determine QOL changes associated with the intervention. Pelvic Floor Therapy Evaluation forms which included visual analog scales (VAS) administered at return treatment sessions, six months and one year will also be analyzed to determine patient compliance with pelvic muscle exercises and recommended bowel treatment plan. Perceived improvement in urinary, defecatory and pelvic pain symptoms will be tracked via the VAS (see appendix C). This data base is ongoing and only data collected up to February 2016 will be analyzed for the purpose of this study. 


\section{Instrumentation}

Three valid and reliable measures were collected for the longitudinal data set to measure the effectiveness of treatment and impact of continuance of learned behavior modification on symptom improvement and quality of life (QOL). The PFDI-20 (see Appendix A) and PFIQ-7 (see Appendix B) questionnaires were used to monitor treatment effect on QOL of this longitudinal study. These validated questionnaires are considered the most rigorous instruments available in assessing life impact and QOL of women with symptoms of PFD. The intended population of both questionnaires includes women with disorders of the pelvic floor including urinary incontinence, pelvic organ prolapse and anal incontinence. The strength of the PFDI-20 is that it is a short form of the PFDI that gives a comprehensive assessment of the effect of pelvic floor disorders on the QOL of women, rather than assessing just one aspect of pelvic floor function such as urinary incontinence. The PFIQ-7 is the short form of the PFIQ and the only questionnaire that assesses life impact in women with pelvic floor disorders. These questionnaires have been translated and validated in several languages, allowing the use of a common tool for evaluation of PFD in different populations and cultures (De Tayrac, Deval, Fernandez, \& Mares. 2007; Kaplan, Sut, N., \& Sut, H. 2012; Teleman, Stenzelius, Iorizzo, \& Jakobsson, 2011).

The validity and responsiveness of PFDI-20 and PFIQ-7 was evaluated in four multi-center studies conducted to develop conversion formulas between the short and long versions. Barber et al (2011) looked at 1006 participants in these prospective studies of pelvic floor disorders who completed the long versions of the PFDI, PFIQ at baseline and three and twelve months after treatment. Responses were used to calculate scores for 
the short versions and correlations were calculated between scale versions using Pearson's correlation coefficient comparing their relative responsiveness using the standardized response mean. The researchers found that the PFDI-20 and PFIQ-7 scale scores demonstrated excellent correlations with their long versions and similar responsiveness at three and twelve months. Responsiveness was good to excellent for PFDI-20 urinary and prolapse scales (SRM -0.71 and -0.85 respectively), moderate for PFDI-20 colorectal scale (SRM-0.73 to -1.09) and each of the PFIQ-7 scales summary scores $(-0.21$ to -0.90$)$. Conversion formulas demonstrated excellent goodness of fit. The short forms provide a reliable and valid alternative in situations where reduced response burden is desired.

The VAS is widely used due to its simplicity and adaptability to a broad range of populations and settings. It is sensitive to small changes and is of most value when measuring changes within individuals, versus comparisons across a group (Hawker, Mian, Kendzerska, \& French, 2011). This instrument was particularly useful in evaluating subject perceived symptom improvement at each session and aided the APRN in determining course of treatment (see Appendix C).

\section{Pelvic Floor Distress Inventory-20 (PFDI-20)}

The PFDI-20 is both a symptom inventory and a measure of the degree of bother and distress (QOL) caused by pelvic floor symptoms. It is a short form version of the Pelvic Floor Distress Inventory. The PFDI-20 includes 20 questions and three scales, Urinary Distress Inventory, Pelvic Organ Prolapse Distress Inventory, and Colorectal Anal Distress Inventory. Each of the three scales are scored from 0 (least distress) to 100 
(greatest distress). The scores are weighted and the sum of the scores of these three scales serves as the overall summary score of the PFDI-20 which ranges from 0 to 300 . (Barber, Walters, \& Bump, 2005).

The PFDI-20 has good test-retest reliability (interclass coefficient $\mathrm{r}=.86, p<.001$ ). Each of the three scales (urinary distress inventory, pelvic organ prolapse distress inventory and colorectal-anal distress inventory) demonstrates significant correlation with their long-form scales $(\mathrm{r}=.86, \mathrm{r}=.92, \mathrm{r}=.93$, respectively, $p<.0001)$. The PFDI-20 has strong construct validity as it demonstrates a significant association with appropriate measures of symptom severity and pelvic floor diagnosis (Barber et al., 2011).

\section{Pelvic Floor Impact Questionnaire-7 (PFIQ-7)}

The PFIQ-7 is a shortened version of the PFIQ and is used to assess life impact, i.e. QOL, in women with pelvic floor disorders. It includes all of the Incontinence Impact Questionnaire-7 as well as items related to other pelvic floor disorders. The PFIQ-7 consists of three scales of seven questions each taken from the Urinary Impact Questionnaire, the Pelvic Organ Prolapse Impact Questionnaire and the Colorectal-Anal Impact Questionnaire. The three scales are scored from 0 (least impact) to 100 (greatest impact) and an overall summary score (0-300). Each of the three scales correlates highly with their long forms $(\mathrm{r}=.96, \mathrm{r}=.96, \mathrm{r}=.94$, respectively, $p<.0001)$. This questionnaire demonstrates construct validity as it demonstrates a significant association with appropriate measures of symptom severity and pelvic floor diagnosis. The PFIQ-7 demonstrates moderate responsiveness (Barber et al., 2011). 


\section{Visual Analog Scale}

Three VAS scales were used to measure perceived improvement in urinary, defecatory and pelvic pain symptoms following initial treatment. The VAS is a straight horizontal line measuring $100 \mathrm{~mm}$. The ends are defined as the extreme limits of the parameters to be measured (urinary, defecatory and pelvic pain symptoms) oriented from left (worse) to the right (best).

The patient is asked to mark on the line the point that they feel represents their perception of their current state. The score is determined by measuring in $\mathrm{mm}$ from the left end of the line to the point that the patient marks. The VAS requires little training to administer and score and has been found to be acceptable to patients. The test-retest reliability has been shown to be good, but higher among literate $(r=0.94, p=0.001)$ than illiterate patients ( $\mathrm{r}=.71, \mathrm{p}=0.001)$ (Hawker et al., 2011).

\section{Demographic and Compliance Data}

Demographic data will be collected and analyzed in an attempt to reveal predictor variables associated with treatment success and failure. The information collected by the APRN at the initial visit will include patient demographics, medical, surgical and obstetrical history, pelvic organ prolapse stage and medications. Data will be collected via the Pelvic Floor Therapy Evaluation form and recorded at subsequent visits by the APRN regarding compliance with behavior modifications to assist in determining predictor variables for long term treatment success. The Pelvic Floor Evaluation form designed specifically for patients returning for the second through the final visit and includes compliance with pelvic muscle exercises (number of times per day exercises 
performed), compliance with the recommended bowel treatment program(frequency of BM, straining and use of bulk forming fiber such as psyllium), use of vaginal estrogen if indicated (dosage and frequency of use) and in some cases adherence to prescribed medication. See appendix C.

\section{Specific Aims}

Specific aim \#1: Identify the immediate and long-term effectiveness of comprehensive pelvic floor rehabilitation on women with urinary, defecatory, pelvic organ prolapse and pelvic pain symptoms.

The hypotheses addressing this aim are:

H1: Women who undergo comprehensive pelvic floor rehabilitation with an APRN will report ongoing improvement in urinary symptoms (via VAS) six months and one year following treatment.

$\mathrm{H} 2$ : Women who undergo comprehensive pelvic floor rehabilitation with an APRN will report ongoing improvement in defecatory symptoms (via VAS) six months and one year following treatment.

H3: Women who undergo comprehensive pelvic floor rehabilitation with an APRN will report ongoing improvement in symptoms of pelvic pain (via VAS) six months and one year following treatment.

H4: Women who undergo comprehensive pelvic floor rehabilitation with an APRN will report improved QOL (via PFDI-20 and PFIQ-7) immediately following treatment, in six months and one year. 
Specific aim \#2: Determine the impact of continuance of learned behavior modification on symptom improvement in women immediately following comprehensive pelvic floor rehabilitation and in six months and one year.

The hypotheses addressing this aim are:

H1: In women who undergo comprehensive pelvic floor therapy with an APRN, greater practice of daily pelvic floor muscle strengthening exercises (group \#1: at least $4 \mathrm{x}$ day compared to group \#2 at least $2 \mathrm{xday}$ ) will be associated with greater symptom improvement (via VAS) six and twelve months following treatment.

H2: In women who undergo comprehensive pelvic floor rehabilitation with an APRN, the extent to which they continue the recommended bowel treatment program (group \#1 compliant compared to group\#2 noncompliant) will be associated with greater symptom improvement (via VAS) six and twelve months following treatment.

\section{Data Set}

This proposed study is a secondary analysis of a unique and robust data set. This data set was collected longitudinally and includes information from 406 women who presented for comprehensive pelvic floor rehabilitation by one of two APRNs at a Midwest academic outpatient urogynecology clinic for symptoms of PFD between February 2013 and February 2016. This secondary analysis will measure symptom improvement and changes in QOL of women with symptoms of PFD immediately following treatment, in six and twelve months. It will also attempt to determine predictor variables contributing to symptom improvement. 


\section{METHODOLOGY}

\section{Design}

A secondary analysis of this data set will be performed. Sample size is 406 women who presented for comprehensive pelvic floor rehabilitation with one of two APRNs from February 2013 to February 2016. Data analysis will include PFDI-20 and PFIQ-7 questionnaires administered at baseline, completion of treatment, six months and one year to determine QOL changes associated with the intervention. Pelvic Floor Therapy Evaluation forms, which included VAS, administered at return treatment sessions, six months and one year will be analyzed to determine perceived improvement in urinary, defecatory and pelvic pain symptoms. The Evaluation form will also track compliance with pelvic muscle exercises and the recommended bowel treatment program to determine if they are associated with symptom improvement at six months and one year following treatment (see appendix C). This data base is ongoing and only data collected up to February 2016 will be analyzed for the purpose of this study.

\section{Proposed Study Limitations}

There are several study limitations that should be considered. Generalizability is a concern as only women presenting to a single Midwest academic urogynecology outpatient clinic are represented in this data set. Also, questionnaire and VAS data analysis will be performed only on those subjects who presented for therapy and returned for multiple subsequent visits, representing some of the most motivated patients. Another limitation is that data are not available for a control group which would have strengthened this secondary analysis. Additionally, though all subjects received similar 
treatment, each subject was assigned to one of two APRNs which could potentially be confounding because of individual provider treatment styles. It will be difficult to discern the effect of individual treatment modalities on subject outcomes as there were multiple interventions administered for each subject, however the primary outcome is the comprehensive management of these subjects.

\section{Inclusion/exclusion criteria}

Only those subjects who completed a course of treatment and returned their six and/or twelve month questionnaires will be analyzed. Questionnaires will not be analyzed on those lost to follow up; however, demographic data for all subjects will be reported.

\section{Data Analysis}

Table 3.1 summarizes the specific aims, hypotheses and overview of the analyses.

Table 3.1 Specific Aims and Hypotheses

\begin{tabular}{|l|l|l|l|}
\hline \multicolumn{1}{|c|}{ Aims } & \multicolumn{1}{c|}{ Hypothesis } & Measures & \multicolumn{1}{c|}{ Analysis } \\
\hline $\begin{array}{l}\text { 1. Identify the } \\
\text { immediate and } \\
\text { long-term } \\
\text { effectiveness of } \\
\text { comprehensive } \\
\text { pelvic floor } \\
\text { rehabilitation on } \\
\text { women with } \\
\text { urinary, } \\
\text { defecatory, and } \\
\text { pelvic pain } \\
\text { symptoms. }\end{array}$ & $\begin{array}{l}\text { H1: Women who undergo } \\
\text { comprehensive pelvic floor } \\
\text { rehabilitation with an } \\
\text { APRN will report ongoing } \\
\text { improvement in urinary } \\
\text { symptoms (via VAS) } \\
\text { months and 1 year } \\
\text { following treatment. }\end{array}$ & VAS & $\begin{array}{l}\text { A repeated measure ANOVA } \\
\text { will be used to analyze these } \\
\text { findings. If the data are not } \\
\text { normally distributed, as } \\
\text { assessed by a combination of } \\
\text { the Shapiro-Wilk test and } \\
\text { visual inspection of the } \\
\text { distribution, a non-parametric } \\
\text { repeated measures test such as } \\
\text { the Friedman's test will be } \\
\text { applied. }\end{array}$ \\
\hline & $\begin{array}{l}\text { H2: Women who undergo } \\
\text { comprehensive pelvic floor } \\
\text { rehabilitation with an } \\
\text { APRN will report ongoing } \\
\text { improvement in defecatory } \\
\text { symptoms (via VAS) } 6\end{array}$ & VAS & $\begin{array}{l}\text { A repeated measure ANOVA } \\
\text { will be used to analyze these } \\
\text { findings. If the data are not } \\
\text { normally distributed, as } \\
\text { assessed by a combination of } \\
\text { the Shapiro-Wilk test and } \\
\text { visual inspection of the }\end{array}$ \\
& & &
\end{tabular}




\begin{tabular}{|c|c|c|c|}
\hline & $\begin{array}{l}\text { months and } 1 \text { year } \\
\text { following treatment. }\end{array}$ & & $\begin{array}{l}\text { distribution, a non-parametric } \\
\text { repeated measures test such as } \\
\text { the Friedman's test will be } \\
\text { applied. }\end{array}$ \\
\hline & $\begin{array}{l}\text { H3: Women who undergo } \\
\text { comprehensive pelvic floor } \\
\text { rehabilitation with an } \\
\text { APRN will report ongoing } \\
\text { improvement in symptoms } \\
\text { of pelvic pain (via VAS) } 6 \\
\text { months and } 1 \text { year } \\
\text { following treatment. }\end{array}$ & VAS & $\begin{array}{l}\text { A repeated measure ANOVA } \\
\text { will be used to analyze these } \\
\text { findings. If the data are not } \\
\text { normally distributed, as } \\
\text { assessed by a combination of } \\
\text { the Shapiro-Wilk test and } \\
\text { visual inspection of the } \\
\text { distribution, a non-parametric } \\
\text { repeated measures test such as } \\
\text { the Friedman's test will be } \\
\text { applied. }\end{array}$ \\
\hline & $\begin{array}{l}\text { H4: Women who undergo } \\
\text { comprehensive pelvic floor } \\
\text { rehabilitation with an } \\
\text { APRN will report improved } \\
\text { QOL (via PFDI-20 and } \\
\text { PFIQ-7) immediately } \\
\text { following treatment, in } 6 \\
\text { months and } 1 \text { year. }\end{array}$ & $\begin{array}{l}\text { PFDI-20 } \\
\text { PFIQ-7 }\end{array}$ & $\begin{array}{l}\text { Repeated measures ANOVA } \\
\text { for each outcome will be used } \\
\text { to analyze this data. A non- } \\
\text { parametric repeated measures } \\
\text { test will be applied if the data } \\
\text { are not normally distributed. }\end{array}$ \\
\hline $\begin{array}{l}\text { 2. Determine the } \\
\text { impact of } \\
\text { continuance of } \\
\text { learned behavior } \\
\text { modification on } \\
\text { symptom } \\
\text { improvement in } \\
\text { women } \\
\text { immediately } \\
\text { following } \\
\text { comprehensive } \\
\text { pelvic floor } \\
\text { rehabilitation and } \\
\text { in } 6 \text { months and } 1 \\
\text { year. }\end{array}$ & $\begin{array}{l}\text { H1: In women who } \\
\text { undergo comprehensive } \\
\text { pelvic floor therapy with an } \\
\text { APRN, greater practice of } \\
\text { daily pelvic floor muscle } \\
\text { strengthening exercises } \\
\text { (group \#1: at least } 4 x d a y \\
\text { compared to group \#2 at } \\
\text { least } 2 \text { xday) will be } \\
\text { associated with greater } \\
\text { symptom improvement (via } \\
\text { VAS) at } 6 \text { and } 12 \text { months } \\
\text { following treatment } \\
\text {. }\end{array}$ & VAS & $\begin{array}{l}\text { Analyses will be performed to } \\
\text { determine distribution of the } \\
\text { data. If the data is normally } \\
\text { distributed, a parametric test } \\
\text { such as ANOVA or Pearson's r } \\
\text { will be performed for the } \\
\text { bivariate analysis. If the data } \\
\text { are not normally distributed a } \\
\text { nonparametric test such as } \\
\text { Kruskal-Wallis or Spearman's } \\
\text { rho will be conducted. } \\
\text { Continuous variables (ie. Age, } \\
\text { BMI, \# of vaginal deliveries) } \\
\text { will be analyzed with the VAS } \\
\text { using Pearson's if normally } \\
\text { distributed or Spearman's rho if } \\
\text { not normally distributed. } \\
\text { Nominal variables (ie. POP, } \\
\text { diabetes, history of obstetrical } \\
\text { injury) will be analyzed with } \\
\text { the VAS using ANOVA if } \\
\text { normal distribution or Kruskal- } \\
\text { Wallis if not normally } \\
\text { distributed. } \\
\text { General linear model ANOVA } \\
\text { on ranks at the three different } \\
\text { time points will be analyzed to } \\
\text { predict the effect of pelvic }\end{array}$ \\
\hline
\end{tabular}




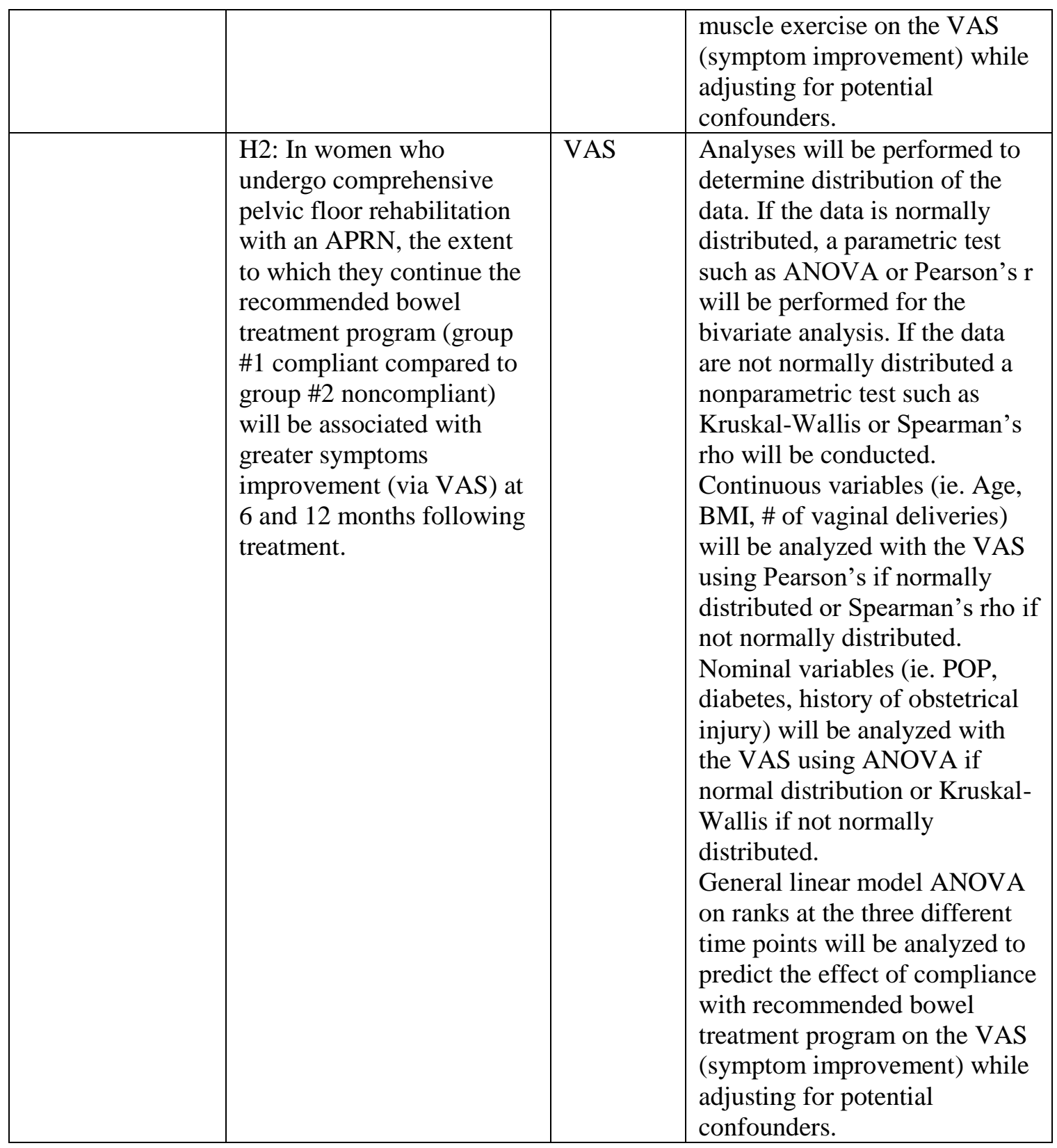

The first aim and hypotheses one through three are focused on symptom improvement which was tracked with a VAS administered on each return visit and at six and twelve months. Data analyzed will report perceived improvement change in urinary, defecatory and pelvic pain symptoms following initiation of treatment and at six and 12 months. A repeated measure ANOVA will be used to analyze these VAS data. If the data 
are not normally distributed, as assessed by a combination of the Shapiro-Wilk test and visual inspection of the distribution, a non-parametric repeated measures test such as the Friedman's test will be applied. The fourth hypothesis is focused on subject change in QOL immediately following the intervention and six and twelve months. The PFDI-20 and PFIQ-7 questionnaires administered at initiation and end of treatment, in six and twelve months will be analyzed. Repeated measures ANOVA for each outcome will be used to analyze this data. A non-parametric repeated measures test will be applied if the data are not normally distributed.

The second specific aim and hypotheses seek to determine the impact of continuance of learned behavior modification on symptom improvement via VAS in women six months and one year following treatment end. Data collected on the Pelvic Floor Therapy Evaluation forms administered at the second through final treatment and at six and twelve months will be entered and analyzed, specifically the number of times a day per day a subject performs pelvic muscle exercises and compliance with the recommended bowel treatment program.

Data for the first hypothesis will be divided into two groups. Group \#1: performs pelvic strengthening exercises at least $4 \mathrm{x}$ day and group \#2: performs pelvic strengthening exercises at least $2 \mathrm{x}$ day. Analyses will be performed to determine distribution of the data. If the data are normally distributed, a parametric test such as ANOVA or Pearson's $r$ will be performed for the bivariate analysis. If the data are not normally distributed a nonparametric test such as Kruskal-Wallis or Spearman's rho will be conducted. Continuous variables (ie. Age, BMI, \# of vaginal delivers, \# of sessions completed) will be analyzed with the VAS using Pearson's if normally distributed or 
Spearman's rho if not normally distributed. Nominal variables (ie. POP, diabetes, history of obstetrical injury) will be analyzed with the VAS using ANOVA if normal distribution or Kruskal-Wallis if the data are not normally distributed. General Linear Models ANOVA on ranks at the three different time points will be analyzed to predict the effect of pelvic muscle strengthening exercise on the VAS (perceived symptom improvement) while adjusting for potential confounders.

Data for the second hypothesis will be divided into two groups. Group \#1: compliance with the recommended bowel treatment program and group \#2: noncompliant with the recommended bowel treatment program. Analyses will be performed to determine distribution of the data. If the data is normally distributed, a parametric test such as ANOVA or Pearson's $r$ will be performed for the bivariate analysis. If the data are not normally distributed a nonparametric test such as Kruskal-Wallis or Spearman's rho will be conducted. Continuous variables (ie. Age, BMI, \# of vaginal deliveries, \# of sessions completed) will be analyzed with the VAS using Pearson's if normally distributed or Spearman's rho if not normally distributed. Nominal variables (ie. POP, diabetes, history of obstetrical injury) will be analyzed with the VAS using ANOVA if the data are normally distributed or Kruskal-Wallis if not normally distributed. General linear model ANOVA on ranks at the three different time points will be analyzed to predict the effect of bowel treatment compliance with VAS (perceived symptom improvement) while adjusting for potential confounders (NCSS 11 Kaysville, Utah). 


\title{
CHAPTER FOUR
}

Manuscript: Outcomes of Comprehensive Management of Pelvic Floor

Dysfunction in Women: A Secondary Analysis

\section{Title}

Outcomes of Comprehensive Management of Pelvic Floor

Dysfunction in Women: A Secondary Analysis

\begin{abstract}
Objective: Traditional management of pelvic floor dysfunction (PFD) in women has followed a clinically compartmentalized and fragmented approach, potentially failing to address multiple etiologies, frequently resulting in incomplete resolution of symptoms. Women with symptomatic PFD often consult with many different health care providers, increasing the potential for duplication and delay in treatment. Multiple referrals can result in increased cost of care and decreased patient satisfaction. Advanced Practice Nurses in a urogynecology clinic are uniquely positioned to provide comprehensive care to women with urinary, defecatory and pelvic pain complaints. The aim of this secondary analysis was to determine immediate and long-term symptom improvement and change in quality of life (QOL) in women with symptoms of PFD who underwent a course of comprehensive pelvic floor rehabilitation with an APRN at an outpatient academic urogynecology clinic.
\end{abstract}


Methods: This study is a secondary analysis of a prospective data set of women who underwent treatment for symptoms of PFD by an APRN between February 2013 and February 2016. Data were analyzed on subjects who completed up to five 30 to $45-$ minute treatment sessions with an APRN which included pelvic muscle biofeedback; vaginal electrogalvanic stimulation; behavior modification; and in some cases pessary fitting or pharmacologic intervention. Data collected included, but was not limited to, validated QOL instruments at baseline (e.g. PFDI-20 and PFIQ-7) and subject perception of symptom improvement as measured by visual analog scale (VAS) at following initiation of treatment; and six and twelve months following treatment completion.

Results: Four hundred twenty-eight subjects were enrolled in the initial database. Data were considered sufficient for analysis among 406 subjects with data available from the initial visit. Demographic data revealed a median age of 51 and median parity of two. Ninety-seven percent were Caucasian and $48 \%$ reported a history of third or fourth degree obstetrical injury. Subjects experienced a statistically significant improvement in QOL, which was durable at one year. VAS results revealed $80 \%$ median perceived improvement in urinary, defecatory, and pain symptoms six and 12 months following treatment. There was insufficient data to determine if compliance with pelvic muscle exercises and constipation management affected symptom improvement 12 months following completion of treatment.

Conclusion: This secondary analysis suggests that comprehensive pelvic floor rehabilitation for women with symptoms of PFD by an APRN is efficacious and results in improved QOL which is durable to one year. 


\section{Introduction}

Pelvic floor dysfunction (PFD) comprises symptoms associated with anatomical and functional disturbances of the lower urinary tract and micturition; lower gastrointestinal tract and defecation; and sexual function and/or pelvic pain (Delancey, 2005; Morgan, Delancey, Guire, \& Fenner, 2007). These symptoms can range from bothersome to debilitating and are challenging to patients and professionals in both primary and specialty care settings. The cost of managing PFD is ever increasing due to rising public expectations of health care, technological advances and increasing prevalence of predisposing factors such as diabetes, obesity and an aging population. Demand for care associated with PFD is predicted to rise by $50 \%$ over the next 30 years, resulting in increased health care cost and Medicare spending (Luber, Boero, \& Choe, 2001).

Symptoms of PFD are common among women of all ages with increasing prevalence in middle aged and older populations. The risk of developing symptoms is estimated at $40 \%$ of women between 65 and 70 years and increases to $50 \%$ in those over 80 (Nygaard, Barber, Burgio, 2008). It is estimated that $11 \%$ of women will undergo surgical intervention for PFD and $30 \%$ will return to surgery as a result of symptom recurrence (Olsen, Smith, Bergstrom, Colling, Clark, 1997).

Pelvic floor disorders often coexist and it is estimated that $23.7 \%$ of women have one or more pelvic floor disorders (Nygaard et al., 2008). As the population ages, health care utilization for PFD is predicted to grow. Wu and colleagues (2010) used US Census Bureau population projections to estimate the total number of women who will undergo 
surgery for pelvic organ prolapse from 2010 to 2050 and determined that this number is expected to increase by $48.2 \%$ over these four decades.

The limitation of studies on health care utilization is that some women with PFD do not seek care. In a population-based sample of women 40 years or older, the prevalence of UI was $41 \%$; but only $25 \%$ of symptomatic women sought care, $23 \%$ received some care, and 12\% received subspecialty care (Minassian et al., 2012). In a community-based Internet survey of women older than 45 years, 19\% reported accidental bowel leakage but only $29 \%$ of those had sought care (Brown, Wexner, \& Lukacz, 2013). Thus, the incidence of care seeking provides an underestimate of the public health burden of PFD among US women.

PFD is a multidisciplinary issue and traditional management has followed a clinically compartmentalized and fragmented approach, potentially failing to address multicompartmental symptomology resulting in incomplete resolution of the problem (Davis, Kumar, \& Wake 2010). Women with PFD often consult with many different health care providers, increasing the potential for duplication and delay in treatment. Patients presenting to their primary care physician with urinary complaints are often referred to a urologist. Those with defecatory symptoms are historically treated by a gastroenterologist or a colorectal surgeon and women with pelvic and/or sexual pain are most often referred to gynecology for evaluation and management. Multiple referrals contribute to increased health care costs and patient frustration with care.

A more standardized comprehensive approach in managing PFD as a single clinical entity would be beneficial to women and potentially decrease cost associated with 
managing the multitude of symptoms associated with PFD. There is considerable evidence supporting the clinical and cost-effectiveness of nurse specialists in the management of urinary incontinence. Advanced practice nurses (APRNs) and Physician Assistants practicing in urology and urogynecology settings are especially qualified to comprehensively manage women with PFD (Newman \& Wein, 2013). They are licensed to perform detailed history and physicals, counsel women on behavior modification including pelvic muscle exercise training, prescribe medication, and fit and manage pessaries if indicated. They often have the luxury of arranging for longer appointment times compared to medical consultations. This ability to nonsurgically manage the multitude of etiologies and symptoms associated with PFD can potentially result in more unified, comprehensive, cost effective care and improved patient satisfaction.

In 2013 this researcher published a retrospective review of 728 women with symptoms of PFD who underwent comprehensive pelvic floor rehabilitation by an APRN in a Midwest Academic female pelvic medicine and reconstructive surgery clinic. Treatment included a conglomeration of pelvic floor muscle training (PFMT), biofeedback, behavior modification, electrogalvanic stimulation (EGS), incontinence devices and various indicated pharmacotherapies. These patients reported a mean symptom improvement of $80-85 \%$ in urinary, defecatory and pelvic pain symptoms after five treatment sessions (Starr et al., 2013). These outcomes are significant, but the women were not prospectively enrolled and were not followed longitudinally after treatment. Several questions remained unanswered including: 1) "How effective is comprehensive management of PFD by an APRN over time?" 2) "If symptom control is maintained, what variables predict symptom stability?" 
The current study is a secondary analysis of a prospective database of women who were referred to these same APRNs for comprehensive treatment of PFD. Validated questionnaires were distributed and demographic data were collected. The subjects were followed for up to one year after completion of treatment in an attempt to gain insight, into the complex management of PFD by an APRN and make a scientific contribution to the literature for non-surgical management of women with these life altering symptoms.

\section{Materials and Methods}

\section{Study Overview}

This secondary analysis of a prospective database was approved by the University of Missouri Health Sciences IRB in 2016. All women $\geq 18$ years of age who presented to this academic outpatient female pelvic medicine and reconstructive surgery practice for comprehensive pelvic floor rehabilitation by an APRN between February 2013 and February 2016 were asked to enroll in the database at the initial visit. There was no incentive offered and the number of subjects that declined to participate or did not return for treatment was recorded. The subjects were scheduled for a total of five visits/appointments with the APRN, either weekly or every other week, depending on financial or time constraints, transportation issues and symptom severity. Those with a primary complaint of pelvic pain were recommended to return weekly for optimal symptom management. Patients who lived a distance from the clinic were offered the option of renting a Pathway STM-10 portable battery-operated EGS device (Prometheus, Dover NH) to perform treatments at home. Two validated QOL questionnaires, Pelvic Floor Distress Inventory-20 (PFDI-20) and Pelvic Floor Impact Questionnaire-7 (PFIQ- 
7) (Barber et al., 2011) (see appendix A\&B) were completed at the first and last treatment session and mailed to the subjects six and twelve months after treatment completion. Visual analog scales (VAS) were used to track changes in subject global impression of symptom improvement at each successive treatment and at six and twelve months. Pelvic Floor Therapy Evaluation Forms (see appendix C) were completed to track subject symptoms and compliance with recommended behavioral therapies such as pelvic muscle exercises and the recommended bowel regimen. Data were analyzed on 406 subjects who completed treatment and were mailed a questionnaire six and 12 month post treatment. Of those 406 subjects 196 completed at least three treatment sessions and completed the VAS and/or PFDI-20 and PFIQ-7 at end treatment. Demographic data were analyzed on all 406 subjects.

\title{
Intervention
}

\begin{abstract}
APRNs Role
Comprehensive pelvic floor rehabilitation was performed by one of two APRNs at this Midwest female pelvic medicine and reconstructive surgery outpatient clinic. The APRNs are board certified family nurse practitioners with a combined experience of 30 years in urology and/or urogynecology and have each been managing women with symptoms of PFD in this clinic for at least eight years. Subjects were directly referred to either of the APRNs by one of two collaborating board certified urogynecologists within the clinic. Outside referrals were common among family practice, gynecology, urology, colorectal and gastroenterology providers. Common referring diagnoses included stress urinary incontinence, urinary urgency/frequency, urgency incontinence, nocturia, voiding
\end{abstract}


dysfunction, incomplete bladder emptying, outlet obstruction defecation, pelvic pain, dyspareunia, hypertonic pelvic floor muscles, pelvic organ prolapse and pelvic muscle weakness.

\section{Comprehensive History and Genitourinary Exam}

The first appointment with the APRN included a complete history and physical with a focus on presenting pelvic floor symptoms. The subject was asked to empty her bladder and a lower abdominal and pelvic exam was performed. Visual examination of the mons, vulva and perineum was completed to assess for skin abnormalities such as abnormal lesions, lichens sclerosis or dermatitis. A vulvar workup was completed (ie: Qtip test, vaginal $\mathrm{pH}$, wet prep and fungal culture) if symptoms of dyspareunia and/or pelvic pain were reported. A 14 French non-dwelling urinary catheter was inserted into the urethra to drain the bladder and measure post void residual if urinary symptoms were reported. Office urinalysis was performed and the specimen was sent for culture if positive for leukocytes, nitrites or blood. Pelvic organ prolapse quantification (Bump et al., 1996) scoring was performed to determine support of the apical, anterior and posterior vaginal compartments. Split speculum examination was performed to assess for vaginal tissue atrophy and abnormal lesions. Digital examination of the levator ani muscles was performed to assess for tone and painful trigger point areas. The subject was asked to perform a pelvic muscle contraction to assess for strength and proper isolation of this muscle group. A rectal exam was then completed to assess for anal tone and perineal support as well as any abnormal findings such as hemorrhoids, fissures or anal/rectal mass. 


\section{Biofeedback}

Biofeedback of the pelvic floor was then performed with use of the Prometheus CTS 2000 (Prometheus, Dover NH). The subject was assisted into a comfortable semirecumbant position with the HOB elevated 20-30 degrees. An abdominal EMG patch was placed on the rectus abdominus muscle just below the umbilicus to monitor accessory muscle during PFM contraction. A vaginal probe was inserted to monitor PFM EMG and in some cases a $3 \mathrm{~cm}$ manometry probe filled with $1.5 \mathrm{cc}$ of air was placed in the anal canal to measure PFM strength and endurance. The subject was able to view the monitor which showed all 3 modalities simultaneously (see figure 2). PFM resting tone was measured by having the subject completely relax for 30 seconds. They were then given verbal cues by the APRN to contract and relax their pelvic floor. Ten, 10 second contraction with 10 second relaxation periods were performed to assess for PFM strength, endurance, fatigue, and change in resting tone. The rectal probe and abdominal patch were then removed. Proper placement of the vaginal probe was confirmed then two pillows were placed under the subjects knees and the legs were extended so that the subject was able to relax.

\section{Vaginal EGS}

Vaginal EGS therapy was then performed for 30 minutes. The APRN chose a frequency and intermittent or constant delivery based on the patients symptoms and initial resting tone. A constant setting was used if the patients PFM resting tone measured $>4$ microvolts, otherwise an intermittent stimulation was delivered 5 seconds on and 5 
seconds off. During the treatment time the amplitude was adjusted by the APRN so that the subject sensed a strong yet not uncomfortable sensation.

\section{Patient Education/Behavior Modification}

Patient education was conducted by the APRN while the subject was undergoing EGS therapy. Pictures of the PFMs and pelvic organs were used to enhance understanding of symptoms. A specific PFM exercise regimen was prescribed based on the individuals PFM strength and endurance. Patients with symptoms of pelvic pain and/or dyspareunia were instructed on PFM relaxation exercises and pelvic stretches. Sitting on a heating pad was recommended twice a day for 20 minutes to help relax the PFMs. Subjects with symptoms of urinary urgency and frequency and/or nocturia were instructed on urge suppression techniques and timed voiding. They were also given a list of foods and beverages that could potentially contribute to their urgency symptoms. Fluid intake was discussed. It was recommended that $64 \mathrm{oz}$ of non-caffeinated beverages be consumed daily. Obese women were counseled on weight loss and referred to the bariatric center if they were interested in a formalized weight loss program. Smoking cessation was also addressed. A bowel regimen including daily use of psyllium fiber and as needed magnesium hydroxide was recommended to facilitate complete emptying of the rectum every morning. As needed use of loperamide was advised for those with symptoms of loose stools, rectal urgency, and/or fecal incontinence. Appropriate teaching handouts were provided for the subject to review at home. 


\section{Additional Treatment Options}

Each visit with the APRN included biofeedback, EGS, behavior modification reinforcement and if indicated constipation management. It was recommended that the patients return every 1-2 weeks for a total of five treatments. If they continued to be bothered by their symptoms after five sessions, other treatment options were offered such as pessary fitting for prolapse or stress urinary incontinence; or medication for remaining symptoms of over-active-bladder. Surgical intervention was an option for women who continued to be bothered by prolapse. Those with stress urinary incontinence who did not desire a pessary were offered placement of a midurethral sling. Those with refractory overactive bladder, incomplete bladder emptying or fecal incontinence were candidates for a trial of sacral neuromodulation.

Medications were sometimes prescribed. Subjects with urogenital atrophy were prescribed Premarin vaginal cream or their current estrogen cream was adjusted at the initial visit. Those still experiencing nocturia after their fourth treatment were offered imipramine $25 \mathrm{mg}$ or melatonin at bedtime though this was rarely necessary. Nocturnal polyuria was ruled out with a patient bladder diary. Those with overactive bladder were offered oxybutynin $5 \mathrm{mg}$ tid prn if they did not desire to take a daily medication for symptom control and were not responding to the treatment which was uncommon. If an antimuscarinic was desired, the patients' insurance plan often influenced the medication prescribed. Solifenacin or mirabegron were often a first choice if affordable. 


\section{Results}

Data were gathered on 406 women between February 2013 and February 2016.

Demographic data revealed a mean age of 51 and body mass index of 29. Most subjects had completed some college education. Median gravity and parity was two with predominantly vaginal deliveries. The number of treatment sessions attended ranged from one to eight with an average total of three. A majority of subjects were Caucasian menopausal women with equal distribution of stage 0-II pelvic organ prolapse. It is worth noting that $50 \%$ of those enrolled reported a history of a third or fourth degree obstetrical laceration with delivery. A majority were sexually active (71\%) with $49 \%$ reporting painful intercourse. Patient characteristics are shown in Table 4.1\&4.2.

Table 4.1. Numerical Demographic Data $(n=406)$

\begin{tabular}{|lcc|}
\hline Measure & Median & Range \\
\hline Age & 51 & $18-88$ \\
\hline BMI & 29 & $17-40$ \\
\hline Education (years) & 14 & $4-20$ \\
\hline Gravidity & 2 & $0-11$ \\
\hline Parity & 2 & $0-11$ \\
\hline Vaginal deliveries & 2 & $0-7$ \\
\hline C-section deliveries & 0 & $0-4$ \\
\hline Term Pregnancies & 2 & $0-8$ \\
\hline Total Sessions of PFT & 3 & $1-8$ \\
\hline Urinary pads per day & 1 & $0-25$ \\
\hline Urinations per day & 2 & $1-9$ \\
\hline Leaks per day & 1 & $0-$ constant \\
\hline Urinations at night & 1.5 & $0-9$ \\
\hline
\end{tabular}


Table 4.2. Categorical Demographic Data $(n=406)$

\begin{tabular}{|c|c|c|}
\hline Measure & Group & Percent \\
\hline Race & Caucasian & 97 \\
\hline \multirow[t]{5}{*}{ Marital Status } & Single & 20 \\
\hline & Married & 63 \\
\hline & Widowed & 9 \\
\hline & Divorced & 6 \\
\hline & Separated & 2 \\
\hline \multirow[t]{6}{*}{ Employment } & Employed & 61 \\
\hline & Unemployed & 5 \\
\hline & Student & 2 \\
\hline & Home Parent & 6 \\
\hline & Retired & 19 \\
\hline & Disabled & 6 \\
\hline \multirow{4}{*}{$\begin{array}{l}\text { Menopause } \\
\text { status }\end{array}$} & Pre- & 45 \\
\hline & Peri- & 5 \\
\hline & Post- & 37 \\
\hline & Surgical & 13 \\
\hline \multirow{4}{*}{$\begin{array}{l}\text { Pelvic Organ } \\
\text { Prolapse (POP) } \\
\text { stage }\end{array}$} & 0 & 34 \\
\hline & 1 & 32 \\
\hline & 2 & 29 \\
\hline & 3 & 4 \\
\hline Hysterectomy & & 40 \\
\hline Prolapse repair & & 11 \\
\hline
\end{tabular}

\begin{tabular}{|lr|}
\hline \multicolumn{1}{|c}{ Measure } & Percent \\
\hline Incontinence surgery & 12 \\
\hline Other pelvic surgery & 48 \\
\hline Smoker & 10 \\
\hline Ever a smoker & 25 \\
\hline $\begin{array}{l}\text { Obstetrical Laceration- } \\
\mathbf{3}^{\text {rd }} \text { or } \mathbf{4}^{\text {th }} \text { degree }\end{array}$ & 50 \\
\hline Sexually active & 71 \\
\hline Diagnosis of stress incontinence & 82 \\
\hline Diagnosis of urge incontinence & 22 \\
\hline Diagnosis of mixed incontinence & 54 \\
\hline Diagnosis of fecal incontinence & 18 \\
\hline Diagnosis of pelvic muscle spasm & 76 \\
\hline Diagnosis of defecatory dysfunction & 71 \\
\hline Diagnosis of pelvic pain & 30 \\
\hline Diagnosis of vaginal pain & 5 \\
\hline Diagnosis of dyspareunia & 49 \\
\hline Wears pads & 56 \\
\hline Bladder empty post void & 32 \\
\hline Medication-narcotic & 8 \\
\hline Medication-anticholinergic & 11 \\
\hline Medication-diuretic & 14 \\
\hline Oral contraceptive & 12 \\
\hline Hormone replacement therapy & 98 \\
\hline Vaginal estrogen & \\
\hline
\end{tabular}

Pelvic Floor Therapy Evaluation forms, which included the VAS were collected from the second through the final visit and at six and 12 months following treatment completion to track changes in bladder, bowel and pelvic pain symptoms. Data collected on the evaluation form included but were not limited to subject perceived global improvement in symptoms via VAS, urinary symptoms, nocturia, pad use, pain scores and frequency of bowel movements (appendix C). Because the VAS measures subject 
perceived symptom improvement, they were administered with each return visit following initiation of treatment and six and 12 months following treatment. See tables 4.3, $4.4 \& 4.5$. The data for this analysis were not normally distributed by Shapiro-Wilk test or visual inspection. Friedman's test (non-parametric, repeated measures) was used to detect significant differences between the VAS score after the final treatment and 6- and 12-month VAS scores; no differences were found, indicating the treatment effect was sustained through 12 months. Subjects reported $80 \%$ median improvement in symptoms at end treatment via VAS and no decline was noted at 6 and 12 months. (Figures 4.1-4.3).

Table 4.3. Percent in Urinary Symptom Improvement by VAS

\begin{tabular}{|r|c|c|c|c|}
\hline \multicolumn{1}{|c|}{$\mathrm{n}$} & Final & 6 months & 12 months & $\mathrm{p}$ \\
\hline 196 & $80(75-80)$ & & & \\
\hline 46 & $81(40-85)$ & $80(74-85)$ & & 0.50 \\
\hline 24 & $84(75-90)$ & & $83(65-90)$ & 0.51 \\
\hline 8 & $81(50-95)$ & $80(50-90)$ & $80(10-90)$ & 0.41 \\
\hline
\end{tabular}

Values are medians $(95 \% \mathrm{Cl})$. $p$ values evaluate for differences between Final visit, 6 month and 12 month time points by Friedman's test for repeated measures.

Table 4.4. Percent in Defecatory Symptom Improvement by VAS

\begin{tabular}{|r|c|c|c|c|}
\hline \multicolumn{1}{|c|}{$\mathrm{n}$} & Final & 6 months & 12 months & $\mathrm{p}$ \\
\hline 196 & $80(75-80)$ & & & \\
\hline 37 & $80(70-90)$ & $80(66-90)$ & & 1.0 \\
\hline 19 & $90(70-99)$ & & $76(57-90)$ & 0.033 \\
\hline 3 & 70 & 60 & 86 & 0.37 \\
\hline
\end{tabular}

Values are medians $(95 \% \mathrm{Cl})$. $p$ values evaluate for differences between Final visit, 6 month and 12 month time points by Friedman's test for repeated measures.

Table 4.5. Percent in Pelvic Pain Symptom Improvement by VAS

\begin{tabular}{|r|c|c|c|c|}
\hline \multicolumn{1}{|c|}{$\mathrm{n}$} & Final & 6 months & 12 months & $\mathrm{p}$ \\
\hline 196 & $80(75-80)$ & & & 0.59 \\
\hline 16 & $75(60-90)$ & $77(50-98)$ & & 0.41 \\
\hline 9 & $80(50-100)$ & & $92(43-100)$ & \\
\hline 1 & 90 & 100 & 100 & \\
\hline
\end{tabular}

Values are medians $(95 \% \mathrm{Cl})$. $p$ values evaluate for differences between Final visit, 6 month and 12 month time points by Friedman's test for repeated measures. 
Figure 4.1. Subject Reported Percentage Urinary Symptom Improvement (VAS)
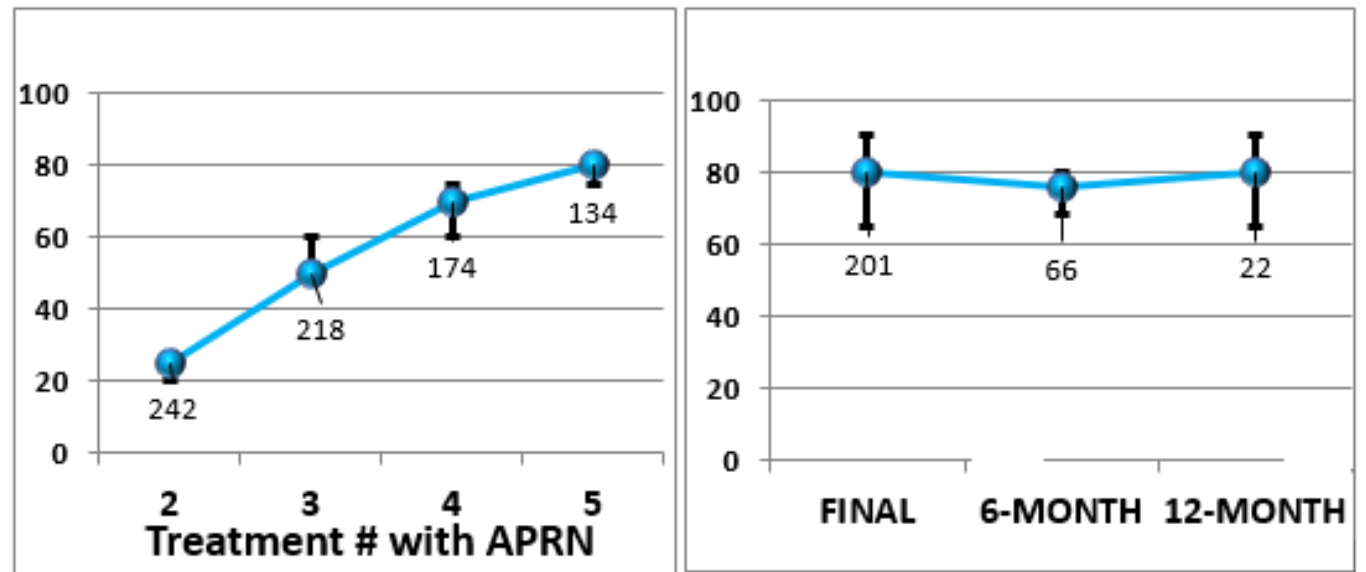

Figure 4.2. Subject Reported Percentage Defecatory Symptom Improvement (VAS)
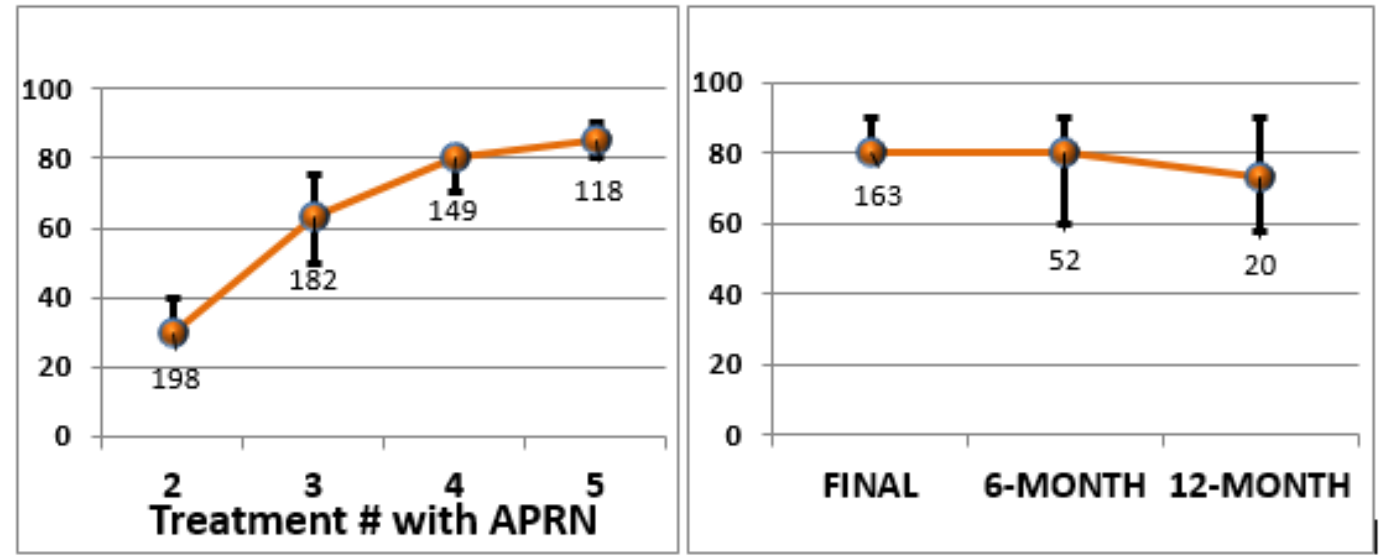

Figure 4.3. Subject Reported Percentage Pelvic Pain Symptom Improvement (VAS)
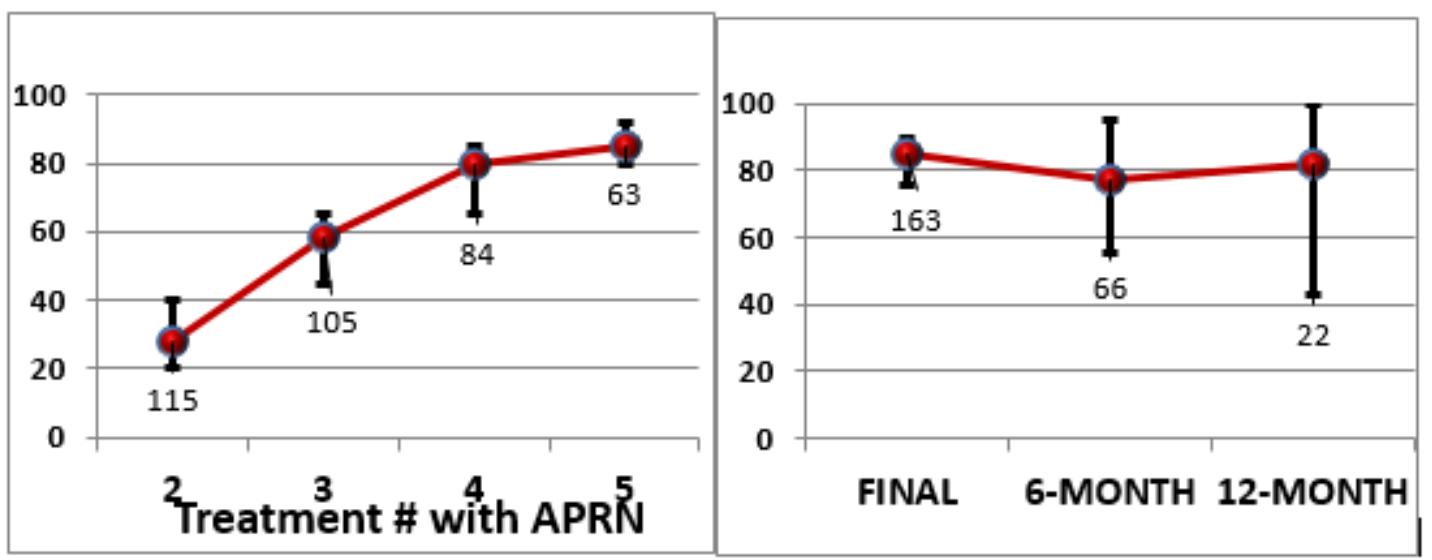
Of the 406 women who enrolled in the study, 196 completed at least three treatment sessions and one or more of the questionnaires at beginning and end of treatment. Outcomes were significant for improvement in QOL (via PFDI-20 \& PFIQ-7) at treatment end and sustained for up to one year. Statistical analysis revealed the results were not normally distributed by Shapiro-Wilk test or visual inspection; therefore, Friedman's test (non-parametric, repeated measures) was used to detect significance (NCSS 11 Kaysville, Utah). Due to missing data at various time points, data were analyzed separately for subjects completing questionnaires. (Tables 4.6, 4.7, 4.8, 4.9)

Table 4.6. QOL Improvement Final Treatment

\begin{tabular}{|l|c|c|c|c|}
\hline Outcome & $\mathrm{n}$ & Initial & Final & $p$ \\
\hline PFDI-20 & 153 & $92(81-102)$ & $38(31-44)$ & 0.000 \\
\hline PFIQ-7 & 147 & $38(33-48)$ & $14(9.5-19)$ & 0.000 \\
\hline
\end{tabular}

Values are medians $(95 \% \mathrm{Cl})$

$p$ values evaluate for differences between Initial and Final visits by Friedman's test

Table 4.7. QOL Improvement Final Treatment \& 6 Months

\begin{tabular}{|l|c|c|c|c|}
\hline Outcome & \multicolumn{1}{c|}{$\mathrm{n}$} & Initial & 6 Months & $p$ \\
\hline PFDI-20 & 100 & $93(79-104)$ & $43(37-55)$ & 0.000 \\
\hline PFIQ-7 & 89 & $43(33-57)$ & $14(9.5-24)$ & 0.000 \\
\hline
\end{tabular}

Values are medians $(95 \% \mathrm{Cl})$

$p$ values evaluate for differences between Initial and Final visits by Friedman's test

Table 4.8. QOL Improvement Final Treatment \& 12 Months

\begin{tabular}{|l|c|c|c|c|}
\hline Outcome & $\mathrm{n}$ & Initial & 12 Months & $p$ \\
\hline PFDI-20 & 37 & $92(73-104)$ & $40(26-66)$ & 0.001 \\
\hline PFIQ-7 & 37 & $38(33-48)$ & $4.8(0-14)$ & 0.001 \\
\hline
\end{tabular}

Values are medians $(95 \% \mathrm{Cl})$

$p$ values evaluate for differences between Initial and Final visits by Friedman's test

Table 4.9. QOL Improvement at All Time Points

\begin{tabular}{|l|c|c|c|c|c|c|}
\hline Outcome & $\mathrm{n}$ & Initial & Final & 6 months & 12 months & $p$ \\
\hline PFDI-20 & 28 & $88(67-96)$ & $27(18-33)$ & $42(21-54)$ & $31(13-52)$ & 0.000 \\
\hline PFIQ-7 & 27 & $38(19-52)$ & $9.5(0-19)$ & $14(0-14)$ & $4.8(0-9.5)$ & 0.001 \\
\hline
\end{tabular}

Values are medians $(95 \% \mathrm{Cl})$

$p$ values evaluate for differences between Final visit, 6 month and 12 month time points by Friedman's test 
Data were also collected to determine if compliance with pelvic floor muscle exercises and compliance with the recommended bowel treatment program affected patient perceived symptom improvement via the VAS. General linear model ANOVA on ranks was used to analyze these data. No relationship was detected between frequency of exercises and reported symptom improvement via VAS for urinary, defecatory and pelvic pain symptoms at end of treatment. See table 4.10. Data analysis revealed no relationship detected between compliance with the recommended bowel treatment program and reported symptom improvement via the VAS for urinary, defecatory and pelvic pain symptoms at end treatment. See table 4.11. Unfortunately, a large percentage of subjects neglected to provide information on daily exercise frequency and compliance with the bowel treatment program when completing the mailed questionnaires. General linear model ANOVA on ranks was used analyze this small data set and no relationship could be determined at the six and 12 month time points.

Table 4.10. End of Treatment Exercise Frequency-Symptom Improvement via VAS

\begin{tabular}{|c||c|c|c|c|c|c|}
\hline $\begin{array}{c}\text { Exercises } \\
\text { per day }\end{array}$ & $\mathrm{n}$ & $\begin{array}{c}\text { Urinary } \\
\text { Symptom Index }\end{array}$ & $\mathrm{n}$ & $\begin{array}{c}\text { Defecatory } \\
\text { Symptom Index }\end{array}$ & $\mathrm{n}$ & $\begin{array}{c}\text { Pelvic Pain } \\
\text { Symptom Index }\end{array}$ \\
\hline \hline $0-2$ & 19 & $88(65-100)$ & 15 & $85(50-99)$ & 9 & $75(40-96)$ \\
\hline $2-4$ & 96 & $80(75-85)$ & 84 & $86(80-90)$ & 36 & $85(80-92)$ \\
\hline$>4$ & 54 & $77(70-80)$ & 35 & $90(80-100)$ & 19 & $90(70-95)$ \\
\hline $\mathrm{p}$ & & 0.73 & \multicolumn{3}{|c}{0.48} & \multicolumn{3}{c|}{0.86} \\
\hline
\end{tabular}

Values are medians $(95 \% \mathrm{Cl}) . p$ values are from general linear model ANOVA on ranks

Table 4.11. End of Treatment Bowel Program Compliance-Symptom Improvement VAS

\begin{tabular}{|c||c|c|c|c|c|c|}
\hline Bowel Program & $\mathrm{n}$ & USI & $\mathrm{n}$ & DSI & $\mathrm{n}$ & PPSI \\
\hline YES & 91 & $80(75-82)$ & 90 & $85(80-90)$ & 9 & $75(40-96)$ \\
\hline NO & 8 & $62(30-95)$ & 7 & $70(19-100)$ & 36 & $85(80-92)$ \\
\hline $\mathrm{p}$ & \multicolumn{3}{|c|}{0.73} & 0.48 & & 0.86 \\
\hline \hline
\end{tabular}

Values are medians $(95 \% \mathrm{Cl}) . p$ values are from general linear models ANOVA on ranks 
In summary, subjects with symptoms of PFD who completed at least three sessions of CPFR with an APRN experienced statistically significant improvement in QOL, which was durable at one year. Patient perceived symptom improvement via the VAS revealed $80 \%$ median improvement in urinary, defecatory, and pain symptoms at the conclusion of treatment which was also durable for up to one year. The data showed significant improvements in symptoms determined by negative Spearman rank correlations $\left(r_{s}\right)$ for nocturia at final treatment $\left(r_{s}=-0.49, p=0.013\right)$ and at one year $\left(r_{s}=-\right.$ $0.29, p=0.012)$; for urinary frequency at final treatment $\left(\mathrm{r}_{\mathrm{s}}=-0.49, p=0.009\right)$ and one year $\left(\mathrm{r}_{\mathrm{s}}=-0.49 ; p=0.0001\right) ;$ for number of daily urinary incontinence incidences at final treatment $\left(\mathrm{r}_{\mathrm{s}}=-0.56, p=0.003\right)$ and at one year $\left(\mathrm{r}_{\mathrm{s}}=-0.56, p=0.003\right)$ and pads used per day at final treatment $\left(r_{\mathrm{s}}=-0.71, p=0.0001\right)$ and one year $\left(\mathrm{r}_{\mathrm{s}}=-0.71, p=0.0001\right)$. To our knowledge, this information has not yet been reported in the literature.

\section{Discussion}

The results of this secondary analysis indicate that women with symptoms of PFD can achieve improvement in QOL for up to one year with 3-5 sessions of CPFR by an APRN. This study is unique in that only women were recruited and followed for up to one year tracking QOL data on urinary, defecatory and pelvic pain symptoms. Previous research has primarily focused on the use of physical therapy administered by a physical therapist or physiotherapist which includes but is not limited to pelvic floor muscle training (PFMT) and biofeedback to treat urinary and fecal incontinence (Barroso, Ramos, Martins-Costa, Sanches, \& Muller, 2004; Bendana et al., 2009; Dumoulin \& Hay-Smith, 2010; Hay-Smith, Herderschee, Dumoulin, \& Herbison, 2012; Norton \& 
Cody, 2012; Rai, Cody, Alhasso, \& Stewart, 2012). None of these researchers followed subjects after completion of treatment.

Patients with symptoms of urinary urgency, frequency and/or incontinence who present to their healthcare provider have historically been offered behavior modification and medication management. The study findings reveal that other interventions such as electrogalvanic stimulation (EGS) therapy and behavior modification can achieve similar if not better outcomes without the added cost and unpleasant side-effects associated with over active bladder medications. Subjects with symptoms of stress urinary incontinence achieved significant improvement in QOL at both end treatment and up to one year. Treatment options for this group of women most often include urethral bulking procedures which must often be repeated every 6 months, pessary fitting/management or surgical intervention with a mesh sling.

One very significant finding of this secondary analysis is the significant improvement in nocturia at end treatment and for up to one year, which was tracked via the Pelvic Floor Therapy Evaluation form. Nocturia is defined as getting up more than once in the night to void and is considered clinically meaningful if a patient voids two or more times nightly. Nocturia is a source of significant bother and is a leading cause of sleep disturbance. It is associated with increased rates of depression, work absenteeism, congestive heart failure, and increased mortality (Dani et al., 2016; Miller et al., 2016). In the elderly, it is associated with increased rates of falls and fractures (Solimen et al., 2016). The guidelines for treatment for nocturia currently recommend behavior modification such as limiting fluids 2 hours before bedtime or taking a diuretic 6 hours prior to bedtime, rather than in the a.m. Medications for nocturia such as imipramine are 
often associated with unpleasant side effects such as constipation, dry mouth, dry eyes and sometimes dizziness. Improvement in nighttime frequency was often noted after 1-2 sessions of therapy and these subjects were thrilled to be getting adequate sleep after many years of getting up two or more times in the night to void.

Patients with symptoms of constipation are historically treated with stimulant laxatives which can cause harm to the small intestine and colon with long term use. These study findings lend evidence to the possibility of another successful treatment option based on behavior modification and EGS therapy. A majority of subjects were using nothing more than a bulk forming laxative such as psyllium fiber at end treatment to achieve almost daily bowel movements without straining. The majority of subjects with symptoms of fecal incontinence responded to daily use of a bulk forming laxative and prn use of loperamide. Those that did not respond to this regimen were referred for a trial of sacral neuromodulation.

To date, when women with bothersome symptoms of pelvic organ prolapse present to their health care provider, they are given three options: 1) do nothing 2) pessary fitting or 3) surgical intervention. However, subjects with stage II or less prolapse (i.e. prolapse that does not extend more than $2 \mathrm{~cm}$ outside of the hymenal ring) reported significant improvement in their prolapse symptoms with EGS treatment, constipation management and daily pelvic floor strengthening exercises. Being able to offer women something other than pessary or surgery has not been reported in the literature.

Another interesting finding is the percentage of subjects who presented for treatment with a history of a third or fourth degree obstetrical injury during childbirth. Of 
those presenting for treatment, $50 \%$ had undergone previous vaginal delivery with injury to the anal sphincter. These findings suggest that women with the aforementioned injuries are at increased risk of symptoms of PFD and beg the question: Would these women benefit from comprehensive pelvic floor rehabilitation soon after delivery to decrease their risk of developing future symptoms of PFD?

Though these findings are impressive, there are several limitations to this study. Ninety-seven percent of the subjects were white and presented for repeated treatments at a single institution, limiting the generalizability of the results. Also, many subjects were lost to follow up, especially at the 12-month time point. Though the research staff was diligent in mailing the questionnaires and attempting to follow up via phone call, it was difficult to contact over $50 \%$ of the subjects following treatment. Also, many of the subjects did not complete the section of the mailed questionnaire asking average number of times a day they performed pelvic muscle exercises making it difficult to discern if compliance with the exercises affected long term symptom stability. Compliance with the bowel regimen was also difficult to track after end treatment; therefore, constipation management as a contributing factor to ongoing symptoms stability is also unclear. Most importantly, because this design lacks a control group, one can only conclude that there is a statistical correlation/association between the treatment and the reported outcome.

This researcher has spent the past nine years talking to and treating women with symptoms of PFD. Women desire more than just medication or surgical options for these life-altering symptoms. Many yearn for information about the possible causes of their symptoms and want to be actively involved in making life-style changes for better symptom management. Having contact with an APRN over a six to10-week time period 
provides an opportunity to focus on this complex conglomeration of symptoms and assist the patient in understanding their diagnoses and treatment plan. Women often make the statement at their last visit that they have, "learned so much about my pelvic floor" as they are given the tools to manage their symptoms over time. Many share their success with friends and family members, leading to self-referrals to the clinic as well as increasing number of referrals from other healthcare providers.

Ongoing research is needed to add to the paucity of literature surrounding nonsurgical management of PFD in women. These study findings reveal that comprehensive pelvic floor rehabilitation by an APRN improves QOL at end treatment and for up to one year. While not all the hypotheses were supported, the findings provide valuable information about long term management of symptoms of PFD and inspired ideas for ongoing research. Future randomized controlled trials are being designed to determine the efficacy of EGS therapy alone as it is thought to be a huge contributor to treatment success and there is little published scientific data regarding the specifics of EGS. 


\section{References}

Abrams, P., Artibani, W., Cardozo, L., Dmochowski, R., van Kerrebroeck, P., Sand, P., \& International Continence, S. (2009). Reviewing the ICS 2002 terminology report: the ongoing debate. Neurourology \& Urodynamics, 28(4), 287. doi: 10.1002/nau.20737

Barber, M. D., Chen, Z., Lukacz, E., Markland, A., Wai, C., Brubaker, L., . . Spino, C. (2011). Further validation of the short form versions of the Pelvic Floor Distress Inventory (PFDI) and Pelvic Floor Impact Questionnaire (PFIQ). Neurourology \& Urodynamics, 30(4), 541-546.

Barber, M. D., Walters, M. D., \& Bump, R. C. (2005). Short forms of two conditionspecific quality-of-life questionnaires for women with pelvic floor disorders (PFDI-20 and PFIQ-7). American Journal of Obstetrics and Gynecology, 193(1), 103-113.

Barroso, J. C., Ramos, J. G., Martins-Costa, S., Sanches, P. R., \& Muller, A. F. (2004). Transvaginal electrical stimulation in the treatment of urinary incontinence. British Journal of Urology International, 93(3), 319-323.

Bendana, E. E., Belarmino, J. M., Dinh, J. H., Cook, C. L., Murray, B. P., Feustel, P. J., \& De, E. J. (2009). Efficacy of transvaginal biofeedback and electrical stimulation in women with urinary urgency and frequency and associated pelvic floor muscle spasm. Urologic Nursing, 29(3), 171-176.

Bezerra, L. R., Vasconcelos Neto, J. A., Vasconcelos, C. T., Karbage, S. A., Lima, A. C., Frota, I. P., . . Augusto, K. L. (2014). Prevalence of unreported bowel symptoms in women with pelvic floor dysfunction and the impact on their quality of life. International Urogynecology Journal, 25(7), 927-933. doi: 10.1007/s00192-0132317-2

Butrick, C. W. (2009). Pelvic floor hypertonic disorders: identification and management. Obstetrics and Gynecologic Clinics of North America, 36(3), 707-722. doi: 10.1016/j.ogc.2009.08.011

Coyne, K. S., Sexton, C. C., Thompson, C. L., Milsom, I., Irwin, D., Kopp, Z. S., . . Wein, A. J. (2009). The prevalence of lower urinary tract symptoms (LUTS) in the USA, the UK and Sweden: results from the Epidemiology of LUTS (EpiLUTS) study. British Journal of Urology International, 104(3), 352-360. doi: 10.1111/j.1464-410X.2009.08427.x

Davis, K., \& Kumar, D. (2003). Pelvic floor dysfunction: a conceptual framework for collaborative patient-centred care. Journal of Advanced Nursing, 43(6), 555-568. 
De Tayrac, R., Deval, B., Fernandez, H., Mares et, P. (2007). Development of a liguistically validated French version of two short-form, condition -specific quality of life questionnaires for women with pelvic floor disorders (PFDI-20 and PFIQ-7). Journal of Gynecology and Obstetrical Biological Reproduction 36(8), 738-748.

Dumoulin, C., \& Hay-Smith, J. (2010). Pelvic floor muscle training versus no treatment, or inactive control treatments, for urinary incontinence in women. Cochrane Database Systematic Review(1), CD005654. doi: 10.1002/14651858.CD005654.pub2

Goode, P. S., Burgio, K. L., Richter, H. E., \& Markland, A. D. (2010). Incontinence in older women. Journal of the American Medical Association, 303(21), 2172-2181.

Handa, V. L., Garrett, E., Hendrix, S., Gold, E., \& Robbins, J. (2004). Progression and remission of pelvic organ prolapse: a longitudinal study of menopausal women. American Journal of Obstetrics and Gynecology, 190(1), 27-32. doi: 10.1016/j.ajog.2003.07.017

Hawker, G. A., Mian, S., Kendzerska, T., \& French, M. (2011). Measures of adult pain: Visual Analog Scale for Pain (VAS Pain), Numeric Rating Scale for Pain (NRS Pain), McGill Pain Questionnaire (MPQ), Short-Form McGill Pain Questionnaire (SF-MPQ), Chronic Pain Grade Scale (CPGS), Short Form-36 Bodily Pain Scale (SF-36 BPS), and Measure of Intermittent and Constant Osteoarthritis Pain (ICOAP). Arthritis Care \& Research, 63(S11), S240-S252. doi: 10.1002/acr.20543

Hay-Smith, J., Dean, S., Burgio, K., McClurg, D., Frawley, H., \& Dumoulin, C. (2015). Pelvic-floor-muscle-training adherence "modifiers": A review of primary qualitative studies-2011 ICS State-of-the-Science Seminar research paper III of IV. Neurourology \& Urodynamics, 34(7), 622-631. doi: 10.1002/nau.22771

Hay-Smith, J., Herderschee, R., Dumoulin, C., \& Herbison, P. (2012). Comparisons of approaches to pelvic floor muscle training for urinary incontinence in women: an abridged Cochrane systematic review. European Journal of Physical and Rehabilitation Medicine, 48(4), 689-705.

Herderschee, R., Hay-Smith, E. J., Herbison, G. P., Roovers, J. P., \& Heineman, M. J. (2011). Feedback or biofeedback to augment pelvic floor muscle training for urinary incontinence in women. Cochrane Database Systematic Review(7), CD009252. doi: 10.1002/14651858.CD009252

Hu, T. W., Wagner, T. H., Bentkover, J. D., LeBlanc, K., Piancentini, A., Stewart, W. F., ... Hunt, T. L. (2003). Estimated economic costs of overactive bladder in the United States. Urology, 61(6), 1123-1128. 
Kaplan, P., Sut, N., Sut, H.(2012). Validation, cultural adaptation and responsiveness of two pelvic-floor- specific quality-of-life questionnaires, PFDI-20 and PFIQ-7, in a Turkish population. European Journal of Obstetrics and Gynecology Reproductive Biology, 162(2). 229-233.

Kinchen, K. S., Long, S., Orsini, L., Crown, W., \& Swindle, R. (2003). A retrospective claims analysis of the direct costs of stress urinary incontinence. International Urogynecology Journal and Pelvic Floor Dysfunction, 14(6), 403-411. doi: $10.1007 / \mathrm{s} 00192-003-1096-6$

Lukacz, E. S., Whitcomb, E. L., Lawrence, J. M., Nager, C. W., \& Luber, K. M. (2009). Urinary frequency in community-dwelling women: what is normal? American Journal of Obstetrics \& Gynecology, 200(5), 552 e551-557. doi: 10.1016/j.ajog.2008.11.006

Mellgren, A., Jensen, L. L., Zetterstrom, J. P., Wong, W. D., Hofmeister, J. H., \& Lowry, A. C. (1999). Long-term cost of fecal incontinence secondary to obstetric injuries. Diseases of the Colon and Rectum, 42(7), 857-865; discussion 865-857.

Norton, C., \& Cody, J. D. (2012). Biofeedback and/or sphincter exercises for the treatment of faecal incontinence in adults. Cochrane Database Systematic Review, 7, CD002111. doi: 10.1002/14651858.CD002111.pub3

Nygaard, I., Barber, M. D., Burgio, K. L., Kenton, K., Meikle, S., Schaffer, J., . . Pelvic Floor Disorders, N. (2008). Prevalence of symptomatic pelvic floor disorders in US women. Journal of the American Medical Association, 300(11), 1311-1316. doi: 10.1001/jama.300.11.1311

Rai, B. P., Cody, J. D., Alhasso, A., \& Stewart, L. (2012). Anticholinergic drugs versus non-drug active therapies for non-neurogenic overactive bladder syndrome in adults. Cochrane Database Systematic Review, 12, CD003193. doi: 10.1002/14651858.CD003193.pub4

Starr, J. A., Drobnis, E. Z., Lenger, S., Parrot, J., Barrier, B., \& Foster, R. (2013). Outcomes of a comprehensive nonsurgical approach to pelvic floor rehabilitation for urinary symptoms, defecatory dysfunction, and pelvic pain. Female Pelvic Medicine and Reconstructive Surgery, 19(5), 260-265. doi: 10.1097/SPV.0b013e31829cbb9b

Subak, L. L., Waetjen, L. E., van den Eeden, S., Thom, D. H., Vittinghoff, E., \& Brown, J. S. (2001). Cost of pelvic organ prolapse surgery in the United States. Obstetrics and Gynecology, 98(4), 646-651. 
Sung, V. W., Clark, M. A., Sokol, E. R., Rardin, C. R., \& Myers, D. L. (2007). Variability of current symptoms in women with pelvic organ prolapse. International Urogynecology Journal and Pelvic Floor Dysfunction, 18(7), 787798. doi: 10.1007/s00192-006-0237-0

Teleman, P., Stenzelius, K., Iorizzo, L., Jakobsson, U. (2011). Validation of the Swedish short forms of the Pelvic Floor Impact Questionnaire (PFIQ-7), Pelvic Floor Distress Inventory (PFDI-20) and Pelvic Organ Prolapse/Urinary Incontinence Sexual Questionnaire (PISQ-12). Acta Obstetrics Gynecology Scandanavia, 90(5),483-487.

Thom, D. H., Nygaard, I. E., \& Calhoun, E. A. (2005). Urologic diseases in America project: urinary incontinence in women-national trends in hospitalizations, office visits, treatment and economic impact. Journal of Urology, 173(4), 1295-1301. doi: 10.1097/01.ju.0000155679.77895.cb

Townsend, M. K., Matthews, C. A., Whitehead, W. E., \& Grodstein, F. (2013). Risk factors for fecal incontinence in older women. American Journal of Gastroenterology, 108(1), 113-119.

Varma, M. G., Brown, J. S., Creasman, J. M., Thom, D. H., Van Den Eeden, S. K., Beattie, M. S., . . . Reproductive Risks for Incontinence Study at Kaiser Research, G. (2006). Fecal incontinence in females older than aged 40 years: who is at risk? Diseases of the Colon and Rectum, 49(6), 841-851. doi: 10.1007/s10350-0060535-0

Wehbe, S. A., Whitmore, K., \& Kellogg-Spadt, S. (2010). Urogenital complaints and female sexual dysfunction (part 1). Journal of Sexual Medicine, 7(5), 1704-1713; quiz 1703, 1714-1705. doi: 10.1111/j.1743-6109.2010.01769.x

Whitehead, W. E., Borrud, L., Goode, P. S., Meikle, S., Mueller, E. R., Tuteja, A., . . . Pelvic Floor Disorders, N. (2009). Fecal incontinence in US adults: epidemiology and risk factors. Gastroenterology, 137(2), 512-517, 517 e511-512. doi: 10.1053/j.gastro.2009.04.054

Wilson, L., Brown, J. S., Shin, G. P., Luc, K. O., \& Subak, L. L. (2001). Annual direct cost of urinary incontinence. Obstetrics \& Gynecology, 98(3), 398-406. 


\title{
CHAPTER FIVE
}

\author{
Conclusion
}

\section{Summary}

There is a paucity of literature evaluating the aggregate clinical effect of comprehensive, multimodal nonsurgical pelvic floor rehabilitation. Current research is primarily focused on the use of physical therapy administered by a physical therapist or physiotherapist which includes but is not limited to pelvic floor muscle training (PFMT) and biofeedback to treat urinary and fecal incontinence (Barroso, Ramos, Martins-Costa, Sanches, \& Muller, 2004; Bendana et al., 2009; Dumoulin \& Hay-Smith, 2010; HaySmith, Herderschee, Dumoulin, \& Herbison, 2012; Norton \& Cody, 2012; Rai, Cody, Alhasso, \& Stewart, 2012). The improvement in symptoms afforded by mono modal PFMT is modest, with approximately $43 \%$ reported improvement in outpatient non-group therapy (Hay-Smith et al., 2012).

The retrospective findings reported by Starr et al., (2013) was the first to report significant symptom improvement following comprehensive pelvic floor rehabilitation by an APRN. The data suggested that women who completed three to five sessions, which included pelvic floor muscle training, biofeedback, behavior modification, EGS and sometimes incontinence devices and pharmacotherapies reported a median improvement of $80 \%$ in urinary, defecatory and pelvic pain symptoms. The recent secondary analysis reproduced these findings in its report of $80 \%$ median symptom improvement sustained at 6 and 12 months. In addition to the retrospective study, the prospective results were 
supported by validated questionnaires which revealed significant improvement in QOL at end treatment which was sustainable for up to one year.

\section{Significance}

Traditional management of PFD in women has followed a clinically compartmentalized and fragmented approach, potentially failing to address multicompartmental symptomology resulting in incomplete resolution of the problem. Women with symptoms PFD often consult with many different health care providers, increasing the potential for duplication and delay in treatment. Multiple referrals can result in increased cost of care and decreased patient satisfaction. Because coexisting pelvic floor disorders are common, evaluation and management of all pelvic floor symptoms by a health care provider specializing in the treatment of PFD could improve overall outcomes for women. APRNs in a urogynecology clinic are uniquely positioned to provide comprehensive care to women with urinary, defecatory and pelvic pain complaints. The research findings have served to advance the science of comprehensive nonsurgical management of symptoms of PFD by an APRN, resulting in improved QOL for women with these life altering symptoms.

A successful comprehensive pelvic floor rehabilitation program is dependent on a number of factors including patient recruitment, clearly defined expectations of treatment outcomes and cost, well-educated and motivated staff, proper billing, coding and reimbursement, and ongoing efforts to maintain compliance in patients returning for treatment. Early on in practice, the researcher contacted referring providers and their staff, informing them of the benefit of this type of treatment plan for women with symptoms of 
PFD and the population of patients that would benefit from this program. The program was promoted at local family practice clinics, OB/GYN clinics, independent/assisted living facilities, fitness centers, and health fairs. Additionally, a multitude of self-referrals were made from friends of women who successfully completed the program. It is likely that one of the biggest reasons for treatment success was the APRNs providing the treatment. They are equipped to address a diversity of pelvic floor health needs that could not be immediately addressed by a physical therapist or physiologist. For example, patients with urogenital atrophy could be prescribed vaginal estrogen, patients with levator spasm could be prescribed muscle relaxants, and patients with pelvic organ prolapse could be fit with pessaries. Although anticholinergic medications could be prescribed this was rarely required. Additionally, the APRNs were trained to administer biofeedback and EGS therapy. The ability to offer this type of comprehensive care was a likely contributor to the success of the program.

Scientifically, it is difficult to determine why this treatment program is such a success. Perhaps regular health professional contact, accountability, and oversight of the patients played a key role in the outcome. In two recent Cochrane reviews of pelvic floor muscle training for the treatment of urinary incontinence, a pattern emerged in which women receiving more health professional contact were more likely to report improvement compared to women doing pelvic floor muscle training with little or no supervision (Herderschee et al. 2011; Hosker et al., 2007). It is unclear whether this improvement is related to the facilitation of patient compliance with various therapeutic modalities, placebo effect from the perception of higher quality care, or a desire of patients to please their caregivers by reporting symptom improvement. Regardless of the mechanism, patient 
satisfaction scores reported for this service through a national patient satisfaction survey (Press-Ganey) were consistently the highest in this university healthcare system, often approaching $97 \%$.

It is important to give each patient a clear expectation regarding potential outcome of comprehensive pelvic floor rehabilitation. Taking into consideration their main complaints, physical examination findings, medical history, cognitive ability, and even financial and transportation options to achieve the best outcome. The APRNs counseled every patient at the initial session regarding expected outcomes. They addressed comorbidities and their effect on success such as morbid obesity, diabetes, smoking, older than 75 years, and prior treatment failure. Those with symptoms of urinary incontinence and minimal comorbidities were told they had a chance of achieving at least $80 \%$ improvement with an average of five treatments if they are compliant with exercises and behavior modification. Those with diagnosis of fecal incontinence and pelvic pain were informed they may require up to eight treatments and possible use of a battery-operated EGS device to perform the treatments at home after their fifth treatment. Data was not collected regarding the compliance of home therapy but it is worth noting that those subjects who were performing EGS therapy at home were less likely to perform daily pelvic floor exercises and recommended behavior modification.

Accurate billing and coding information is necessary to assure success when incorporating comprehensive pelvic floor rehabilitation into clinical practice. The companies that manufacture the equipment are often adept at providing this information. Medicare reimbursement differs across the country and will often cover the treatments if the patient has a diagnosis of urinary or fecal incontinence. It is also prudent to include a 
diagnostic code of pelvic muscle weakness or pelvic muscle spasm. Some insurers have a cap on the number of physical therapy sessions they will cover; those who had undergone physical therapy before or after comprehensive pelvic floor rehabilitation did not report a problem with reimbursement for treatments within the same year. The billing codes used do not negate coverage for treatment with a licensed physical therapist. Many clinics set up a system of prior authorization for treatment to determine patient out-of pocket expense. Patients with limited financial resources can be given the option of home EGS therapy and follow up every 4 weeks until they have completed 10 to 12 weeks of treatment. To date, Medicare reimbursement for biofeedback and EGS can differ according to region. These findings will add to the paucity of literature regarding the benefits and cost effectiveness of this comprehensive therapy. Hopefully other researchers will step up and reproduce these findings which could ultimately motivate Medicare and private health insurers to offer consistent reimbursement for the treatment.

These study findings detailing the comprehensive nonsurgical management of PFD in women are the first to scientifically measure QOL outcomes at end treatment and for up to one year. Data collection for six and twelve month post treatment is ongoing for those subjects that completed treatment within the past 12 months. The data base will allow for future analysis on areas such as demographics to reveal which patients are most likely to benefit from treatment and which are more likely to be compliant with behavior modification and completion of treatment. Analysis of the EMG and anal manometry data may reveal insight into changes in pelvic muscle strengthening and specific EGS frequencies most likely to benefit certain diagnoses. 


\section{Future Research}

Ongoing research in the nonsurgical management of women with symptoms of PFD is necessary to advance the science in this field. The next step is to increase the level of evidence by breaking down the individual treatment modalities and design trials to include control groups. A recent Cochrane review of the efficacy of EGS in the treatment of urinary incontinence concluded that EGS shows promise in treating $\mathrm{OAB}$, compared to no active treatment, placebo/sham treatment, pelvic floor muscle training and drug treatment. The authors stated that adding EGS to other treatments such as pelvic floor muscle training may be beneficial however, the quality of evidence is low and more adequately powered studies should be carried out measuring subjective outcomes and adverse effects (Stewart et al 2016).

The results of the secondary analysis revealed positive long term outcomes in symptom control following treatment, however it did not analyze or measure QOL on specific types of urinary incontinence. Future research is needed comparing women with stress, urge or mixed incontinence who undergo vaginal EGS vs sham treatment alone. There is an effort currently underway with the manufacturer of the EGS equipment to design a sham device and begin safety testing. Research questions of interest include "what is the difference between women with symptoms of overactive bladder who undergo EGS therapy compared to women with symptoms of overactive bladder who undergo EGS sham treatment?" Another understudied area is the use of specific frequencies for vaginal EGS therapy. The manufacturers of the equipment provide guidelines, none of which are based on high levels of scientific evidence. The goal is to develop specific treatment guidelines 
so that these programs can be easily incorporated into a medical outpatient setting, increasing access to care for women with symptoms of PFD.

Women with symptoms of PFD should have easy access to programs designed to comprehensively treat this sometimes complex presentation of symptoms. Specific treatment guidelines are being developed so that this type of program can be easily and affordably incorporated into a medical outpatient setting. The more evidence that can be collected and published can potentially increase the number of providers who are willing to set up this type of program in their clinic increasing affordable access to care for women with symptoms of PFD. 


\section{Appendix A. Pelvic Floor Dysfunction Index-20 (PFDI-20)}

\section{PELVIC FLOOR DISTRESS INVENTORY (PFDI)}

Please answer each question by marking an $\mathrm{X}$ in the box with the best response. While answering these questions, please consider your symptoms over the last 3 months. We realize that you may not be having problems in some of these areas, but please fill out this form as completely as possible.

\section{How Much Does this Bother You? Symptom Scale: \\ $1=$ Not at All $2=$ Somewhat $3=$ Moderately $4=$ Quite a bit}

\begin{tabular}{|c|c|c|}
\hline Do You... & NO & \begin{tabular}{|l|} 
YES \\
\end{tabular} \\
\hline 1. Usually experience pressure in the lower abdomen? & $\begin{array}{ll}0 \\
\square\end{array}$ & 1234 \\
\hline 2. Usually experience heaviness or dullness in the pelvic area? & $\begin{array}{l}0 \\
\square\end{array}$ & 1234 \\
\hline $\begin{array}{l}\text { 3. Usually have a bulge or something falling out that you can see or feel in } \\
\text { your vaginal area? }\end{array}$ & 0 & 1234 \\
\hline $\begin{array}{l}\text { 4. Ever have to push on the vagina or around the rectum to have or } \\
\text { complete a bowel movement? }\end{array}$ & 0 & 1234 \\
\hline 5. Usually experience a feeling of incomplete bladder emptying? & 0 & 1234 \\
\hline $\begin{array}{l}\text { 6. Ever have to push up on a bulge in the vaginal area with your fingers to } \\
\text { start or complete urination? }\end{array}$ & 0 & 12234 \\
\hline
\end{tabular}

(Office Use Only) POPDI Score:

\begin{tabular}{|c|c|c|}
\hline Do You... & NO & YES \\
\hline 7. Feel you need to strain too hard to have a bowel movement? & 0 & 1234 \\
\hline $\begin{array}{l}\text { 8. Feel you have not completely emptied your bowels at the end of a } \\
\text { Bowel movement? }\end{array}$ & 0 & 1234 \\
\hline 9. Usually lose stool beyond your control if your stool is well formed? & 0 & 1234 \\
\hline 10. Usually lose stool beyond your control if your stool is loose? & $\begin{array}{l}0 \\
\square\end{array}$ & 1234 \\
\hline 11. Usually lose gas from the rectum beyond your control? & 0 & 1234 \\
\hline 12. Usually have pain when you pass your stool? & 0 & 12344 \\
\hline $\begin{array}{l}\text { 13. Experience a strong sense of urgency and have to rush to the } \\
\text { bathroom to have a bowel movement? }\end{array}$ & 0 & 1234 \\
\hline $\begin{array}{l}\text { 14. Does part of your bowel ever pass through the rectum and bulge } \\
\text { outside during or after a bowel movement? }\end{array}$ & 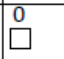 & 1234 \\
\hline
\end{tabular}

(Office Use Only) CRADI Score:

\begin{tabular}{|c|c|c|}
\hline Do You... & NO & YES \\
\hline 15. Usually experience frequent urination? & $\begin{array}{ll}0 \\
\square\end{array}$ & 1234 \\
\hline $\begin{array}{l}\text { 16. Usually experience urine leakage associated with a feeling of urgency, } \\
\text { that is, a strong sensation of needing to go to the bathroom? }\end{array}$ & $\begin{array}{l}0 \\
\square\end{array}$ & 1234 \\
\hline $\begin{array}{l}\text { 17. Usually experience urine leakage related to coughing, sneezing or } \\
\text { laughing? }\end{array}$ & 0 & 1234 \\
\hline 18. Usually experience small amounts of urine leakage (that is, drops)? & $\begin{array}{l}0 \\
\square\end{array}$ & $\begin{array}{l}1234 \\
\square \square \\
\square\end{array}$ \\
\hline 19. Usually experience difficulty emptying your bladder? & $\begin{array}{l}0 \\
\square\end{array}$ & $\begin{array}{l}1234 \\
\square \square \\
\square\end{array}$ \\
\hline $\begin{array}{l}20 . \text { Usually experience pain or discomfort in the lower abdomen or genital } \\
\text { region? }\end{array}$ & 0 & $\begin{array}{l}1234 \\
\square \square\end{array}$ \\
\hline
\end{tabular}

(Office Use Only) UDI Score: 


\section{Appendix B. Pelvic Floor Impact Questionnaire-7 (PFIQ-7)}

\section{Pelvic Floor Impact Questionnaire (PFIQ)}

INSTRUCTIONS: Some women find that bladder, bowel or vaginal symptoms affect their activities, relationships and feelings. For each question, please CIRCLE the response that best describes how much your activities, relationships or feelings have been affected by your bladder, bowel or vaginal symptoms or conditions over the last 3 months. Please be sure to make an answer in

ALL 3 columns for each question.

\begin{tabular}{|c|c|c|c|}
\hline $\begin{array}{l}\text { How do symptoms or conditions relate to the following } \\
\text { Usually affect the following... }\end{array}$ & $\begin{array}{l}\text { Bladder or } \\
\text { Urine } \\
\text { (UIQ) }\end{array}$ & $\frac{\frac{\text { Bowel or }}{\text { Rectum }}}{\text { (CRAIQ) }}$ & $\begin{array}{l}\text { Vagina or } \\
\text { Pelvis } \\
\text { (POPIQ) }\end{array}$ \\
\hline $\begin{array}{l}\text { 1. Ability to do household chores (cooking, } \\
\text { housecleaning, laundry)? }\end{array}$ & $\begin{array}{l}\text { Not at all } \\
\text { Somewhat } \\
\text { Moderately } \\
\text { Quite a bit }\end{array}$ & $\begin{array}{l}\text { Not at all } \\
\text { Somewhat } \\
\text { Moderately } \\
\text { Quite a bit }\end{array}$ & $\begin{array}{c}\text { Not at all } \\
\text { Somewhat } \\
\text { Moderately } \\
\text { Quite a bit }\end{array}$ \\
\hline $\begin{array}{l}\text { 2. Ability to do physical activities such as walking, } \\
\text { swimming, or other exercise? }\end{array}$ & $\begin{array}{l}\text { Not at all } \\
\text { Somewhat } \\
\text { Moderately } \\
\text { Quite a bit }\end{array}$ & $\begin{array}{l}\text { Not at all } \\
\text { Somewhat } \\
\text { Moderately } \\
\text { Quite a bit }\end{array}$ & $\begin{array}{c}\text { Not at all } \\
\text { Somewhat } \\
\text { Moderately } \\
\text { Quite a bit }\end{array}$ \\
\hline $\begin{array}{l}\text { 3. Entertainment activities such as going to a } \\
\text { movie or concert? }\end{array}$ & $\begin{array}{l}\text { Not at all } \\
\text { Somewhat } \\
\text { Moderately } \\
\text { Quite a bit }\end{array}$ & $\begin{array}{l}\text { Not at all } \\
\text { Somewhat } \\
\text { Moderately } \\
\text { Quite a bit }\end{array}$ & $\begin{array}{c}\text { Not at all } \\
\text { Somewhat } \\
\text { Moderately } \\
\text { Quite a bit }\end{array}$ \\
\hline $\begin{array}{l}\text { 4. Ability to travel by car or bus for a distance greater } \\
\text { that } 30 \text { minutes away from home? }\end{array}$ & $\begin{array}{l}\text { Not at all } \\
\text { Somewhat } \\
\text { Moderately } \\
\text { Quite a bit }\end{array}$ & $\begin{array}{l}\text { Not at all } \\
\text { Somewhat } \\
\text { Moderately } \\
\text { Quite a bit }\end{array}$ & $\begin{array}{c}\text { Not at all } \\
\text { Somewhat } \\
\text { Moderately } \\
\text { Quite a bit }\end{array}$ \\
\hline 5. Participating in socialactivities outside your home> & $\begin{array}{c}\text { Not at all } \\
\text { Somewhat } \\
\text { Moderately } \\
\text { Quite a bit }\end{array}$ & $\begin{array}{c}\text { Not at all } \\
\text { Somewhat } \\
\text { Moderately } \\
\text { Quite a bit }\end{array}$ & $\begin{array}{c}\text { Not at all } \\
\text { Somewhat } \\
\text { Moderately } \\
\text { Quite a bit }\end{array}$ \\
\hline 6. Emotional health (nervousness, depression, etc)? & $\begin{array}{l}\text { Not at all } \\
\text { Somewhat } \\
\text { Moderately } \\
\text { Quite a bit }\end{array}$ & $\begin{array}{l}\text { Not at all } \\
\text { Somewhat } \\
\text { Moderately } \\
\text { Quite a bit }\end{array}$ & $\begin{array}{c}\text { Not at all } \\
\text { Somewhat } \\
\text { Moderately } \\
\text { Quite a bit }\end{array}$ \\
\hline 7. Feeling frustrated? & $\begin{array}{l}\text { Not at all } \\
\text { Somewhat } \\
\text { Moderately } \\
\text { Quite a bit }\end{array}$ & $\begin{array}{l}\text { Not at all } \\
\text { Somewhat } \\
\text { Moderately } \\
\text { Quite a bit }\end{array}$ & $\begin{array}{c}\text { Not at all } \\
\text { Somewhat } \\
\text { Moderately } \\
\text { Quite a bit }\end{array}$ \\
\hline
\end{tabular}

(Office Use Only) SCORE: 
Appendix C. Pelvic Floor Therapy Evaluation Form

WOMENS HEALTH CENTER

Framale CONTINENCE AND AdVANCED PELVIC SURGFRY

Department of Obstetrics, Gynecology and Women's Health

\section{Pelvic Floor Therapy Evaluation}

Number of times a day you do pelvic exercises? Are you doing heat therapy? Yes No (circle one)

\section{Place Patient Sticker Here}

Are you doing stretching exercises? Yes No (circle one)

\section{Urinary Symptoms (complete this section ONLY if it applies to you):}

PAD SIZE (clrcle): LIner, Small, Medlum, Large, DlaperiDepends Number of pads used per day?

How many times (average) do you go to the bathroom during the day? $\begin{array}{lllll}3-6 & 7-10 & 11-14 & 15-19 & 20+\end{array}$

Average \# of leaks dally? What were you dolng when you leaked?

Do you "dribble" after volding? Do you feel you completely empty when you vold?

Do you have urinary urgency? Average number of times you get up at night to urinate?

If you get up at night to urinate, does it bother you? Never Mlldly Moderate Severe

Please rate your urinary symptom improvement since your INITIAL session of therapy:

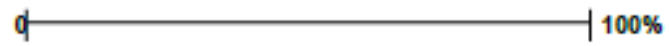

\section{Bowel Symptoms (complete this section ONLY if it applies to you):}

\# of bowel movements per day? \# of times you feit constipated since last visit?

\# of eplsodes of stool inconunence since your last visit? Do you use a flber supplement?

If yes, what flber supplement? Other laxatlves used?

Do you have rectal pressure? Do you empty completely when having a bowel movement?

Please rate your bowel symptoms improvement since your INITIAL session of therapy:

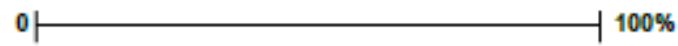

\section{Pelvic Pain Symptoms (complete this section ONLY if it applies to you):}

Rate your pain (0-10) over the past week: What makes your pain better?

What makes your pain worse?

If pain ls primarlly with intercourse, have you trled intercourse since your last visit? Please rate your pelvic pain symptom improvement since your INITIAL session of therapy:

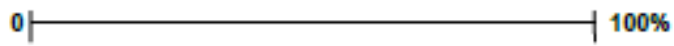




\section{Appendix D. IRB Approval letter}

\section{방}

Institutional Review Board

University of Missouri-Columbia

190 Galena Hall; Dc074.00

Columbia, MO 65212

573-882-3181

irb@missouri.edu

March 23, 2016

Principal Investigator: Julie Ann Starr

Department: Ob, Gyn \& Women's Health

Your Data Analysis Application to project entitled The immediate and long-term effectiveness of comprehensive pelvic floor rehabilitation by an APRN on women with urinary, defecatory, pelvic organ prolapse and pelvic pain symptoms was reviewed and approved by the MU Institutional

Review Board according to the terms and conditions described below:

$\begin{array}{ll}\text { IRB Project Number } & 2005284 \\ \text { IRB Review Number } & 214318\end{array}$

Initial Application Approval Date March 22, 2016

IRB Expiration Date

March 22, 2017

Level of Review

Expedited

Project Status

Closed - Data Analysis Only

Expedited Categories

45 CFR 46.110.a(f)(5)

Risk Level

45 CFR 46.110.a(f)(7)

Type of Consent

Minimal Risk

Written Consent 


\section{Bibliography}

Abbott, J. A., Jarvis, S. K., Lyons, S. D., Thomson, A., \& Vancaille, T. G. (2006). Botulinum toxin type A for chronic pain and pelvic floor spasm in women: a randomized controlled trial. Obstetrics and Gynecology, 108(4), 915-923. doi: 10.1097/01.AOG.0000237100.29870.cc

Abrams, P., Artibani, W., Cardozo, L., Dmochowski, R., van Kerrebroeck, P., Sand, P., \& International Continence, S. (2009). Reviewing the ICS 2002 terminology report: the ongoing debate. Neurourology \& Urodynamics, 28(4), 287. doi: $10.1002 /$ nau.20737

Adelowo, A., Hacker, M., Shapiro, A., Modest, A., Elkadry, E. (2013). Botulinum toxin type A (BOTOX) for refractory myofascial pelvic pain. Female Pelvic Medicine \& Reconstructive Surgery, 19(5), 288-292. doi: 10.1097/SPV.0b013e3182989fd8. PMID: 23982578

Andromanakos, N. P., Kouraklis, G., \& Alkiviadis, K. (2011). Chronic perineal pain: Current pathophysiological aspects, diagnostic approaches and treatment. European Journal of Gastroenterology and Hepatology, 23(1), 2-7. doi: 10.1097/MEG.0b013e32834164f6

Barber, M. D., Chen, Z., Lukacz, E., Markland, A., Wai, C., Brubaker, L., . . Spino, C. (2011). Further validation of the short form versions of the Pelvic Floor Distress Inventory (PFDI) and Pelvic Floor Impact Questionnaire (PFIQ). Neurourology \& Urodynamics, 30(4), 541-546.

Barber, M. D., Walters, M. D., \& Bump, R. C. (2005). Short forms of two conditionspecific quality-of-life questionnaires for women with pelvic floor disorders (PFDI-20 and PFIQ-7). American Journal of Obstetrics and Gynecology, 193(1), $103-113$.

Barroso, J. C., Ramos, J. G., Martins-Costa, S., Sanches, P. R., \& Muller, A. F. (2004). Transvaginal electrical stimulation in the treatment of urinary incontinence. British Journal of Urology International, 93(3), 319-323.

Beco, J., Sulu, M., \& Schaaps, J. P. (1987). A new approach to urinary continence disorders in women: urodynamic ultrasound examination by the vaginal route. Journal de Gynecologic, Obstetrique et Biologic de la Reproduction, 16(987998).

Bendana, E. E., Belarmino, J. M., Dinh, J. H., Cook, C. L., Murray, B. P., Feustel, P. J., $\&$ De, E. J. (2009). Efficacy of transvaginal biofeedback and electrical stimulation in women with urinary urgency and frequency and associated pelvic floor muscle spasm. Urologic Nursing, 29(3), 171-176. 
Bezerra, L. R., Vasconcelos Neto, J. A., Vasconcelos, C. T., Karbage, S. A., Lima, A. C., Frota, I. P., . . Augusto, K. L. (2014). Prevalence of unreported bowel symptoms in women with pelvic floor dysfunction and the impact on their quality of life. International Urogynecology Journal, 25(7), 927-933. doi: 10.1007/s00192-0132317-2

Bertolasi, L., Frasson, E., Cappelletti, J.Y., Vicentini, S., Bordignon, M., Graziottin, A. (2009). Botulinum neurotoxin type A injections for vaginismus secondary to vulvar vestibulitis syndrome. Obstetrics \& Gynecology, 114(5), 1008-1016. doi: 10.1097/AOG.0b013e3181bb0dbb. PMID: 20168100

Bhide, A.A. (2013). Botulinum neurotoxin type A injection of the pelvic floor muscle in pain due to spasticity: a review of the current literature. International Urogynecology Journal, 24: 1429-1434.

Billingham, R. P., Isler, J. T., Friend, W. G., \& Hostetler, J. (1987). Treatment of Levator Syndrome Using High Voltage Electrogalvanic Stimulation. Diseases of the Colon and Rectum, 30, 584-587.

Bleijenberg, G., \& Kuijpers, H. C. (1987). Treatment of the spastic pelvic floor syndrome with biofeedback. Diseases of the Colon and Rectum, 30(2), 108-111.

Bø, K., \& Finckenhagen, H. B. (2001). Vaginal palpation of pelvic floor muscle strength: Inter-test reproducibility and comparison between palpation and vaginal squeeze pressure. Acta Obstetricia et Gynecologica Scandinavica, 80(10), 883-887. doi: 10.1034/j.1600-0412.2001.801003.x

Brown, H.W., Wexner, S.D., \& Lukacz, E.S. (2013). Factors associated with care seeking among women with accidental bowel leakage. Female Pelvic Medicine \& Reconstructive Surgery, 19(2), 66-71. doi:10.1097/SPV.0b013e31828016d3.

Butrick, C. W. (2009). Pelvic floor hypertonic disorders: identification and management. Obstetrics and Gynecologic Clinics of North America, 36(3), 707-722. doi: 10.1016/j.ogc.2009.08.011

Butrick, C.W. (2009). Pathophysiology of pelvic floor hypertonic disorders. Obstetrics \& Gynecology Clinics of North America, 12(36), 699-705.

Chiarioni, G., Nardo, A., Vantini, I., Romito, A., \& Whitehead, W. E. (2010). Biofeedback Is Superior to Electrogalvanic Stimulation and Massage for Treatment of Levator Ani Syndrome. Gastroenterology, 138(4), 1321-1329. doi: 10.1053/j.gastro.2009.12.040 
Coyne, K. S., Sexton, C. C., Thompson, C. L., Milsom, I., Irwin, D., Kopp, Z. S., . . Wein, A. J. (2009). The prevalence of lower urinary tract symptoms (LUTS) in the USA, the UK and Sweden: results from the Epidemiology of LUTS (EpiLUTS) study. British Journal of Urology International, 104(3), 352-360. doi: 10.1111/j.1464-410X.2009.08427.x

Crisp, C.C., Vaccaro, C.M., Estanol, M.V., Oakley, S.H., Kleeman, S.D., Fellner, A.N., Pauls, R.N. (2013). Intra-vaginal diazepam for high-tone pelvic floor dysfunction: a randomized placebo-controlled trial. International Urogynecololgy Journal, 24(11), 1915-23. doi: 10.1007/s00192-013-2108-9.PMID: 23681047

Davis, K., Kumar, S., \& Stanton, R. (2003). Pelvic floor dysfunction: the need for a multidisciplinary team approach. Journal of Pelvic Medicine \& Surgery, 9(1), 23-36.

Davis, K., \& Kumar, S. (2003). Pelvic floor dysfunction: a conceptual framework for collaborative patient-centred care. Journal of Advanced Nursing, 43(6), 555-568.

De Tayrac, R., Deval, B., Fernandez, H., Mares et, P. (2007). Development of a liguistically validated French version of two short-form, condition -specific quality of life questionnaires for women with pelvic floor disorders (PFDI-20 and PFIQ-7). Journal of Gynecology and Obstetrical Biological Reproduction 36(8), 738-748.

Dietz, H. P., Jarvis, S. K., \& Vancaillie, T. G. (2002). The assessment of levator muscle strength: a validation of three ultrasound techniques. International Urogynecology Journal, 13, 156-159.

Dumoulin, C., \& Hay-Smith, J. (2010). Pelvic floor muscle training versus no treatment, or inactive control treatments, for urinary incontinence in women. Cochrane Database Systematic Review(1), CD005654. doi: 10.1002/14651858.CD005654.pub2

El-Khawand, D., Wehbe, S., Whitmore, K. (2013). Botulinum toxin for conditions of the female pelvis. International Urogynecology Journal, 24(7), 1073-1081. doi: 10.1007/s00192-012-2035-1. Review. PMID: 23344218

Finamore, P. S., Goldstein, Howard B., Whitmore, Kristene E. (2008). Pelvic Floor Muscle Dysfunction: A Review. Pelvic Medicine and Surgery, 14(6), 5-22. doi: 10.1097/SPV.Obo13e3181907870

Fitzgerald, C. M., Neville, C. E., Mallinson, T., Badillo, S. A., Hynes, C. K., \& Tu, F. F. (2011). Pelvic floor muscle examination in female chronic pelvic pain. Journal of Reproductive Medicine, 56(3-4), 117-122. 
Fitzgerald, M. P., Anderson, R. U., Potts, J., Payne, C. K., Peters, K. M., Clemens, J. Q., . . Nyberg, L. M. (2009). Randomized Multicenter Feasibility Trial of Myofascial Physical Therapy for the Treatment of Urological Chronic Pelvic Pain Syndromes. The Journal of Urology, 182(2), 570-580. doi:

10.1016/j.juro.2009.04.022

Fouad, L.S., Chen, A.H., Pettit, P.D., Micallef, A. (2015). Transvaginal Trigger Point Injections for Pelvic Floor Myofascial Spasm: A Retrospective Review of Pain Assessment and Development of a Treatment Algorithm. Journal of Minimally Invasive Gynecology, 22(6S), S247-S248. doi: 10.1016/j.jmig.2015.08.864. PMID: 27679176

Goode, P. S., Burgio, K. L., Richter, H. E., \& Markland, A. D. (2010). Incontinence in older women. Journal of the American Medical Association, 303(21), 2172-2181.

Grant, S. R., Salvati, E. P., \& Rubin, R. J. (1975). Levator syndrome: an analysis of 316 cases. Diseases of the Colon and Rectum, 18(2), 161-163.

Handa, V. L., Garrett, E., Hendrix, S., Gold, E., \& Robbins, J. (2004). Progression and remission of pelvic organ prolapse: a longitudinal study of menopausal women. American Journal of Obstetrics and Gynecology, 190(1), 27-32. doi: 10.1016/j.ajog.2003.07.017

Hawker, G. A., Mian, S., Kendzerska, T., \& French, M. (2011). Measures of adult pain: Visual Analog Scale for Pain (VAS Pain), Numeric Rating Scale for Pain (NRS Pain), McGill Pain Questionnaire (MPQ), Short-Form McGill Pain Questionnaire (SF-MPQ), Chronic Pain Grade Scale (CPGS), Short Form-36 Bodily Pain Scale (SF-36 BPS), and Measure of Intermittent and Constant Osteoarthritis Pain (ICOAP). Arthritis Care \& Research, 63(S11), S240-S252. doi: 10.1002/acr.20543

Hay-Smith, J., Dean, S., Burgio, K., McClurg, D., Frawley, H., \& Dumoulin, C. (2015). Pelvic-floor-muscle-training adherence "modifiers": A review of primary qualitative studies-2011 ICS State-of-the-Science Seminar research paper III of IV. Neurourology \& Urodynamics, 34(7), 622-631. doi: 10.1002/nau.22771

Hay-Smith, J., Herderschee, R., Dumoulin, C., \& Herbison, P. (2012). Comparisons of approaches to pelvic floor muscle training for urinary incontinence in women: an abridged Cochrane systematic review. European Journal of Physical and Rehabilitation Medicine, 48(4), 689-705.

Herderschee, R.1., Hay-Smith, E.J., Herbison, G.P., Roovers, J.P., \& Heineman, M.J. (2011). Feedback or biofeedback to augment pelvic floor muscle training for urinary incontinence in women. Cochrane Database Systematic Review, 6(7). CD009252. doi:10.1002/14651858. 
Hosker, G., Cody, J., \& Norton, C. (2007). Electrical stimulation for fecal incontinence in adults. Cochrane Database Systematic Review, (3). CD001310

Hu, T. W., Wagner, T. H., Bentkover, J. D., LeBlanc, K., Piancentini, A., Stewart, W. F., ... Hunt, T. L. (2003). Estimated economic costs of overactive bladder in the United States. Urology, 61(6), 1123-1128.

Hull, T. L., Milsom, J. W., Church, J., Oakley, J., Lavery, I., \& Fazio, V. (1993). Electrogalvanic stimulation for levator syndrome: How effective is it in the long term? Diseases of the Colon and Rectum, 36(8), 731-733. doi: $10.1007 / \mathrm{bf} 02048360$

Kaplan, P., Sut, N., Sut, H.(2012). Validation, cultural adaptation and responsiveness of two pelvic-floor- specific quality-of-life questionnaires, PFDI-20 and PFIQ-7, in a Turkish population. European Journal of Obstetrics and Gynecology Reproductive Biology, 162(2). 229-233.

Kinchen, K. S., Long, S., Orsini, L., Crown, W., \& Swindle, R. (2003). A retrospective claims analysis of the direct costs of stress urinary incontinence. International Urogynecology Journal and Pelvic Floor Dysfunction, 14(6), 403-411. doi: 10.1007/s00192-003-1096-6

Lukacz, E. S., Whitcomb, E. L., Lawrence, J. M., Nager, C. W., \& Luber, K. M. (2009). Urinary frequency in community-dwelling women: what is normal? American Journal of Obstetrics \& Gynecology, 200(5), 552 e551-557. doi: 10.1016/j.ajog.2008.11.006

Jarvis, S. K., Abbott, J. A., Lenart, M. B., Steensma, A., \& Vancaillie, T. G. (2004). Pilot study of botulinum toxin type $\mathrm{A}$ in the treatment of chronic pelvic pain associated with spasm of the levator ani muscles. Australia New Zealand Journal of Obstetrics and Gynaecology, 44(1), 46-50. doi: 10.1111/j.1479828X.2004.00163.x

Kegel, A. H. (1948). Progressive resistance exercise in the functional restoration of the perineal muscles. American Journal of Obstetrics and Gynecology, 56, 238-249.

Langford, C. F., Udvari Nagy, S., \& Ghoniem, G. M. (2007). Levator ani trigger point injections: An underutilized treatment for chronic pelvic pain. Neurourology Urodynamics, 26(1), 59-62. doi: 10.1002/nau.20393

Lukban, J. C., \& Whitmore, K. E. (2002). Pelvic floor muscle re-education treatment of the overactive bladder and painful bladder syndrome. Clinical Obstetrics and Gynecology, 45(1), 273-285. doi: 10.1097/00003081-200203000-00028

McGivney, J. Q., \& Cleveland, B. R. (1965). The Levator Syndrome and Its Treatment. Southern Medical Journal, 58, 505-510. 
Mellgren, A., Jensen, L. L., Zetterstrom, J. P., Wong, W. D., Hofmeister, J. H., \& Lowry, A. C. (1999). Long-term cost of fecal incontinence secondary to obstetric injuries. Diseases of the Colon and Rectum, 42(7), 857-865; discussion 865-857.

Messelink, B., Benson, T., Berghmans, B., Bo, K., Corcos, J., Fowler, C., Van Kerrebroeck, P. (2005). Standardization of terminology of pelvic floor muscle function and dysfunction: report from the pelvic floor clinical assessment group of the International Continence Society. Neurourology Urodynamics, 24(4), 374380. doi: 10.1002/nau.20144

Moldwin, R.M. \& Fariello, J.Y. (2013). Myofascial Trigger Points of the Pelvic Floor: Associations with Urological Pain Syndromes and Treatment Strategies Including Injection Therapy. Current Urology Report, 14, 409. doi:10.1007/s11934-0130360-7

Morris, L., \& Newton, R. A. (1987). Use of High Voltage Pulsed Galvanic Stimulation for Patients with Levator Ani Syndrome. Physical Therapy, 67(10), 1522-1525.

Morrissey, D.1., El-Khawand, D., Ginzburg, N., Wehbe, S., O'Hare, P., Whitmore, K. (2015). Botulinum Toxin A Injections Into Pelvic Floor Muscles Under Electromyographic Guidance for Women With Refractory High-Tone Pelvic Floor Dysfunction: A 6-Month Prospective Pilot Study. Female Pelvic Medicine \& Reconstructive Surgery, 21(5):277-282. doi: 10.1097/SPV.0000000000000177.

Nesbitt-Hawes, E.M., Won, H., Jarvis, S.K., Lyons, S.D., Vancaillie, T.G., Abbott, J.A. (2012). Improvement in pelvic pain with botulinum toxin type A - Single vs. repeat injections. Toxicon, 63:83-87. doi: 10.1016/j.toxicon.2012.11.018. PMID: 23220489

Nicosia, J. F., \& Abcarian, H. (1985). Levator syndrome. A treatment that works. Diseases of the Colon and Rectum, 28(6), 406-408.

Norton, C., \& Cody, J. D. (2012). Biofeedback and/or sphincter exercises for the treatment of faecal incontinence in adults. Cochrane Database Systematic Review, 7, CD002111. doi: 10.1002/14651858.CD002111.pub3

Nygaard, I., Barber, M. D., Burgio, K. L., Kenton, K., Meikle, S., Schaffer, J., . . Pelvic Floor Disorders, N. (2008). Prevalence of symptomatic pelvic floor disorders in US women. Journal of the American Medical Association, 300(11), 1311-1316. doi: 10.1001/jama.300.11.1311

Minassian, V.A., Yan, X.S., \& Lichtenfeld, M.J. (2012). The iceberg of health care utilization in women with urinary incontinence. International Urogynecology Journal, 23, 1087-1093. 
Norton, C., \& Cody, J.D. (2012). Biofeedback and/or sphincter exercises for the treatment of faecal incontinence in adults. Cochrane Database Systematic Review, (7). CD002111.

Nygaard, I., Barber, M. D., Burgio, K. L., Kenton, K., Meikle, S., \& Schaffer, J. (2008). Prevalence of symptomatic pelvic floor disorders in US women. Journal of the American Medical Association, 300(11), 1311-1316. doi: 10.1001/jama.300.11.1311

Oliver, G. C., Rubin, R. J., Salvati, E. P., \& Eisenstat, T. E. (1985). Electrogalvanic stimulation in the treatment of levator syndrome. Diseases of the Colon and Rectum, 28(9), 662-663.

Oyama, I. A., Rejba, A., Lukban, J. C., Fletcher, E., Kellogg-Spadt, S., Holzberg, A. S., \& Whitmore, K. E. (2004). Modified Thiele massage as therapeutic intervention for female patients with interstitial cystitis and high-tone pelvic floor dysfunction. Urology, 64(5), 862-865. doi: 10.1016/j.urology.2004.06.065

Paradis, H., \& Marganoff, H. (1969). Rectal pain of extrarectal origin. Diseaes of the Colon and Rectum, 12(4), 306-312.

Peters, K. M., Carrico, D. J., Kalinowski, S. E., Ibrahim, I. A., \& Diokno, A. C. (2007). Prevalence of Pelvic Floor Dysfunction in Patients with Interstitial Cystitis. Urology, 70(1), 16-18. doi: 10.1016/j.urology.2007.02.067

Rai, B.P., Cody, J.D., \& Alhasso, A. (2010). Anticholinergic drugs versus non-drug active therapies for non-neurogenic overactive bladder syndrome in adults. Cochrane Database Systematic Review, (12). CD003193.

Rai, B. P., Cody, J. D., Alhasso, A., \& Stewart, L. (2012). Anticholinergic drugs versus non-drug active therapies for non-neurogenic overactive bladder syndrome in adults. Cochrane Database Systematic Review, 12, CD003193. doi: 10.1002/14651858.CD003193.pub4

Rao, S. S., Paulson, J., Mata, M., \& Zimmerman, B. (2009). Clinical trial: effects of botulinum toxin on Levator ani syndrome--a double-blind, placebo-controlled study. Alimentary Pharmacology \& Therapeutics, 29(9), 985-991. doi: 10.1111/j.1365-2036.2009.03964.x

Rogalski, M., Kellogg-Spadt, S., Hoffmann, A., Fariello, J., \& Whitmore, K. (2010). Retrospective chart review of vaginal diazepam suppository use in high-tone pelvic floor dysfunction. International Urogynecology Journal, 21(7), 895-899. doi: 10.1007/s00192-009-1075-7

Romito, S., Bottanelli, M., Pellegrini, M., Vicentini, S., Rizzuto, N., \& Bertolasi, L. (2004). Botulinum toxin for the treatment of genital pain syndromes. Gynecology Obstetrics Investigation, 58(3), 164-167. doi: 10.1159/000079620 
Sinaki, M., Merritt, J. L., \& Stillwell, G. K. (1977). Tension myalgia of the pelvic floor. Mayo Clintologyical Proc, 52(11), 717-722.

Sohn, N., Weinstein, M. A., \& Robbins, R. D. (1982). The levator syndrome and its treatment with high-voltage electrogalvanic stimulation. [Case Reports]. American Journal of Surgery, 144(5), 580-582.

Starr, J.A., Drobnis, E.Z., Lenger, S., Parrot, J., Barrier, B., \& Foster, R.T. (2013). Outcomes of a comprehensive nonsurgical approach to pelvic floor rehabilitation for urinary symptoms, defecatory dysfunction, and pelvic pain. Female Pelvic Medicine \& Reconstructive Surgery, 19(5), 260-265. doi: 10.1097/SPV.0b013e31829cbb9b.

Stewart, F., Gameiro, L., El Dib, R., Gameiro, M., Kapoor, A., \& Amaro, J. (2016).

Electrical stimulation with non-implanted electrodes for overactive bladder in adults. Cochrane Database Systematic Review, 9(12). CD010098. doi:10.1002/14651858.CD010098.pub4.

Stoker, J., Halligan, S., \& Bartram, C. (2001). Pelvic floor imaging. Radiology, 218, 621641.

Subak, L.L., Waetjen, L.E., Van den Eeden, S., Thom, D.H., Vittinghoff, E., \& Brown, J.S. (2001). Cost of pelvic organ prolapse surgery in the United States. Obstetrics \& Gynecology, 98(4), 646-51.

Sung, V. W., Clark, M. A., Sokol, E. R., Rardin, C. R., \& Myers, D. L. (2007). Variability of current symptoms in women with pelvic organ prolapse. International Urogynecology Journal and Pelvic Floor Dysfunction, 18(7), 787798. doi: 10.1007/s00192-006-0237-0

Sung, V.W., Washington, B., \& Raker, C.A. (2010). Costs of ambulatory care related to female pelvic floor disorders in the United States. American Journal of Obstetrics \& Gynecology, 202(5), 483.

Teleman, P., Stenzelius, K., Iorizzo, L., Jakobsson, U. (2011). Validation of the Swedish short forms of the Pelvic Floor Impact Questionnaire (PFIQ-7), Pelvic Floor Distress Inventory (PFDI-20) and Pelvic Organ Prolapse/Urinary Incontinence Sexual Questionnaire (PISQ-12). Acta Obstetrics Gynecology Scandanavia, 90(5),483-487.

Thom, D. H., Nygaard, I. E., \& Calhoun, E. A. (2005). Urologic diseases in America project: urinary incontinence in women-national trends in hospitalizations, office visits, treatment and economic impact. Journal of Urology, 173(4), 1295-1301. doi: 10.1097/01.ju.0000155679.77895.cb

Townsend, M. K., Matthews, C. A., Whitehead, W. E., \& Grodstein, F. (2013). Risk factors for fecal incontinence in older women. American Journal of Gastroenterology, 108(1), 113-119. 
Thiele, G. H. (1937). Coccygodynia and pain in the superior gluteal region. Journal of the American Medical Association, 109.

Thiele, G. H. (1963). Coccygodynia: Cause and Treatment. Dis Colon Rectum, 6, 422436.

Thomson, A. J. M., Jarvis, S. K., Lenart, M., Abbott, J. A., \& Vancaillie, T. G. (2005). The use of botulinum toxin type A (BOTOX $\left.{ }^{\circledR}\right)$ as treatment for intractable chronic pelvic pain associated with spasm of the levator ani muscles. BJOG: An International Journal of Obstetrics and Gynaecology, 112(2), 247-249. doi: 10.1111/j.1471-0528.2004.00315.x

Townsend, M.K., Matthews, C.A., Whitehead, W.E., \& Grodstein, F. (2013). Risk factors for fecal incontinence in older women. American Journal of Gastroenterology, 108(1), 113-9. doi: 10.1038/ajg.2012.364.

Tu, F. F., As-Sanie, S., \& Steege, J. F. (2005). Musculoskeletal causes of chronic pelvic pain: a systematic review of existing therapies: part II. Obstetrical and Gynecolgical Survey, 60(7), 474-483.

Varma, M. G., Brown, J. S., Creasman, J. M., Thom, D. H., Van Den Eeden, S. K., Beattie, M. S., . . . Reproductive Risks for Incontinence Study at Kaiser Research, G. (2006). Fecal incontinence in females older than aged 40 years: who is at risk? Diseases of the Colon and Rectum, 49(6), 841-851. doi: 10.1007/s10350-0060535-0

Vonthein, R., Heimerl, T., Schwandner, T., \& Ziegler, A. (2013) Electrical stimulation and biofeedback for the treatment of fecal incontinence: a systematic review. International Journal of Colorectal Diseases, 28(11), 1567-77. doi: 10.1007/s00384-013-1739-0

Wehbe, S. A., Whitmore, K., \& Kellogg-Spadt, S. (2010). Urogenital complaints and female sexual dysfunction (part 1). Journal of Sexual Medicine, 7(5), 1704-1713. doi: 10.1111/j.1743-6109.2010.01769.x

Weiss, J. M. (2001). Pelvic floor myofascial trigger points: Manual therapy for interstitial cystitis and the urgency-frequency syndrome. Journal of Urology, 166(6), 22262231 .

Whitehead, W. E., Borrud, L., Goode, P. S., Meikle, S., Mueller, E. R., Tuteja, A., . . Pelvic Floor Disorders, N. (2009). Fecal incontinence in US adults: epidemiology and risk factors. Gastroenterology, 137(2), 512-517, 517 e511-512. doi: 10.1053/j.gastro.2009.04.054

Wilson, L., Brown, J. S., Shin, G. P., Luc, K. O., \& Subak, L. L. (2001). Annual direct cost of urinary incontinence. Obstetrics \& Gynecology, 98(3), 398-406. 
Wu, J.M., Kawasaki, A., \& Hundley, A.F. (2011). Predicting the number of women who will undergo incontinence and prolapse surgery, 2010 to 2050. American Journal of Obstetrics \& Gynecology, 205, 230.e1-230.e5 


\section{VITA}

Julie Ann Starr was born to Franklin "Frank" and Suzanne "Susie" Stork (Behrend) on November 17, 1963 in the rural town of Tyndall, South Dakota. She was soon joined by two sisters, Nancy and Judi and brother John. Julie's family moved from South Dakota to Alabama to Colorado and finally settled in Jefferson City, Missouri. She graduated from Jefferson City High School in 1982 and attended the University of Missouri, Columbia until 1987 where she earned her Bachelors Degree in Nursing from Sinclair School of Nursing (SSON). Julie spent the first 15 years of her nursing career working in the intensive care units at Boone Hospital Center. She then returned to SSON to receive her Masters Degree in 2008 and assumed her role as a Family Nurse Practitioner at the University of Missouri Health Care, Center for Female Continence and Advanced Pelvic Surgery. For the past ten years she has been treating women with symptoms of pelvic floor dysfunction (PFD), including bladder, bowel and pelvic pain complaints with pelvic floor biofeedback, electrogalvanic stimulation (EGS) and behavior modification. Most of these women overcame their symptoms after five treatment sessions and were able to avoid surgical and/or medication management. Due to lack of scientific evidence in this area, she pursued her doctoral degree at SSON so that she could successfully design and conduct studies on the nonsurgical management of PFD with biofeedback and EGS. Julie hopes that all women will eventually have access to this treatment regimen and gain the knowledge necessary to maintain the health of their pelvic floor for a lifetime. 